This document was prepared in conjunction with work accomplished under Contract No. DE-AC09-96SR18500 with the U. S. Department of Energy.

\title{
DISCLAIMER
}

This report was prepared as an account of work sponsored by an agency of the United States Government. Neither the United States Government nor any agency thereof, nor any of their employees, nor any of their contractors, subcontractors or their employees, makes any warranty, express or implied, or assumes any legal liability or responsibility for the accuracy, completeness, or any third party's use or the results of such use of any information, apparatus, product, or process disclosed, or represents that its use would not infringe privately owned rights. Reference herein to any specific commercial product, process, or service by trade name, trademark, manufacturer, or otherwise, does not necessarily constitute or imply its endorsement, recommendation, or favoring by the United States Government or any agency thereof or its contractors or subcontractors. The views and opinions of authors expressed herein do not necessarily state or reflect those of the United States Government or any agency thereof. 
Key Words:

Performance Assessment

Low-Level Waste

Trigger Value

Retention: Permanent

\section{AUTOMATED GROUNDWATER SCREENING}

Author: Glenn A. Taylor

Co-Author: Leonard B. Collard

REPORT DATE: OCTOBER 31, 2005

Westinghouse Savannah River Company
Savannah River Site
Aiken, SC 29808
$\begin{aligned} & \text { Prepared for the U.S. Department of Energy } \\ & \text { Under Contract Number DEAC09-96-SR18500 }\end{aligned}$
SAVANNAH RIVER NATIONAL LABORATORY




\section{DISCLAIMER}

This report was prepared for the United States Department of Energy under Contract No. DE-AC09-96SR18500 and is an account of work performed under that contract. Neither the United States Department of Energy, nor WSRC, nor any of their employees makes any warranty, expressed or implied, or assumes any legal liability or responsibility for accuracy, completeness, or usefulness, of any information, apparatus, or product or process disclosed herein or represents that its use will not infringe privately owned rights. Reference herein to any specific commercial product, process, or service by trade name, trademark, name, manufacturer or otherwise does not necessarily constitute or imply endorsement, recommendation, or favoring of same by Westinghouse Savannah River Company or by the United States Government or any agency thereof. The views and opinions of the authors expressed herein do not necessarily state or reflect those of the United States Government or any agency thereof.

Printed in the United States of America

Prepared For

U.S. Department of Energy 
Key Words:

Performance Assessment

Low-Level Waste

Trigger Value

Retention: Permanent

\title{
AUTOMATED GROUNDWATER SCREENING
}

\author{
Author: Glenn A. Taylor
}

Co-Author: Leonard B. Collard

\section{REPORT DATE: OCTOBER 31, 2005}

Westinghouse Savannah River Company Savannah River Site

Aiken, SC 29808

Prepared for the U.S. Department of Energy

Under Contract Number DEAC09-96-SR18500

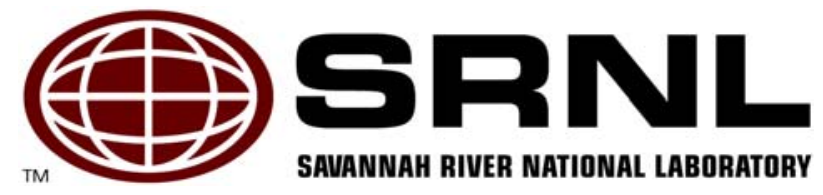




\section{REVIEWS AND APPROVALS}

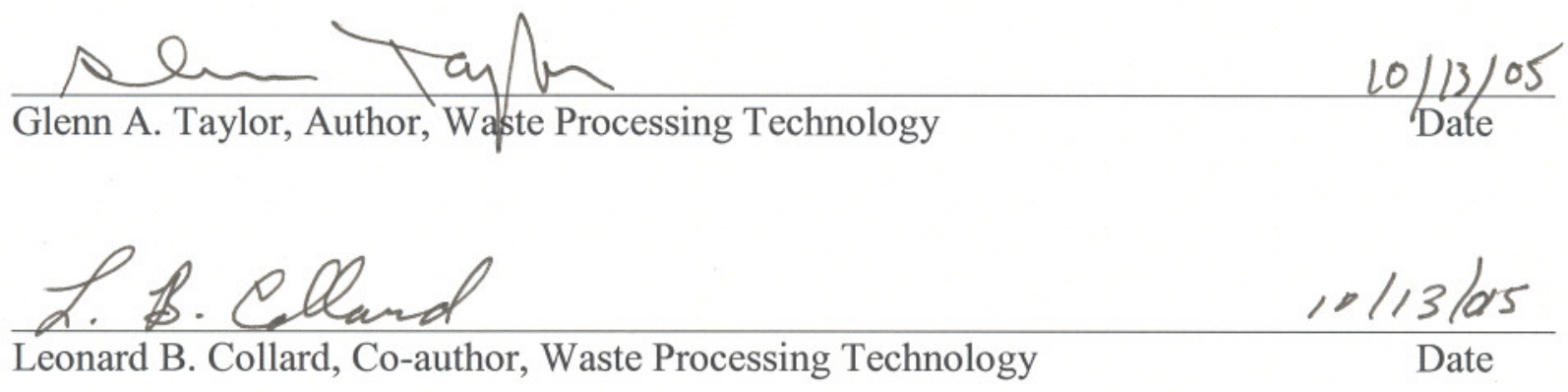

Lany Dikothmen

L. D. Koffman, Peer Reviewer, Engineering Development

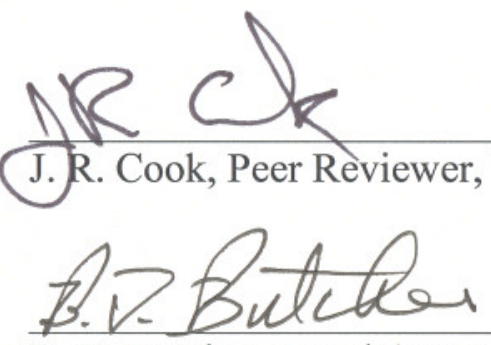

B. T. Butcher, Level 4 Manager, Waste Processing Technology

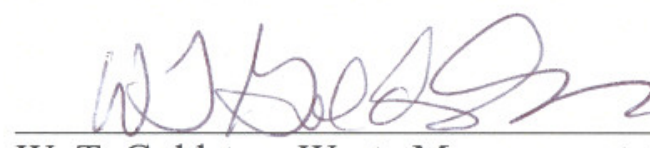

W. T. Goldston, Waste Management Area Project

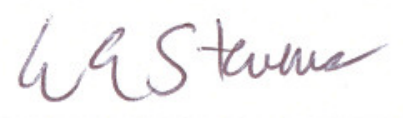

W. E. Stevens, Level 3 Manager, Waste Processing Technology
$10 / 27 / 05$

Date

$10-19-05$

Date

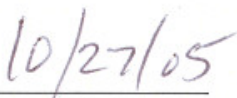

Date 


\section{TABLE OF CONTENTS}

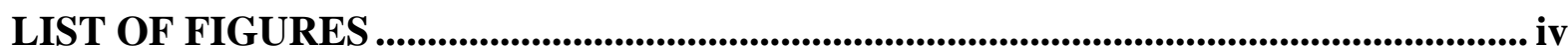

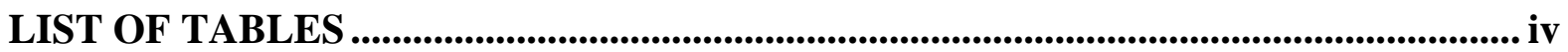

LIST OF ACRONYMS ................................................................................................................

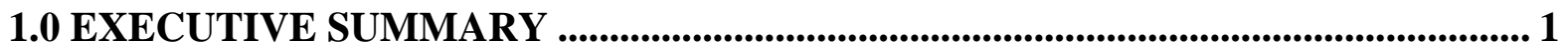

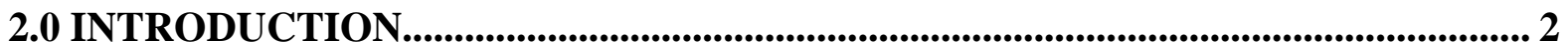

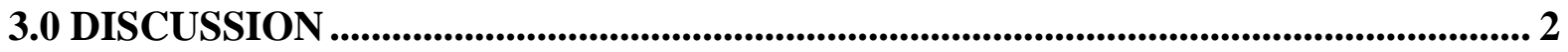

3.1 Methodology ........................................................................................................................... 2

3.1.1 NCRP methodology ....................................................................................................... 2

3.1.1.1 Initial inventory............................................................................................. 2

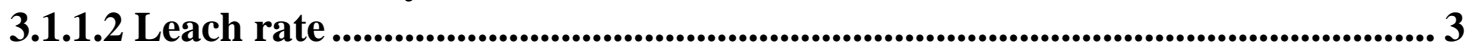

3.1.1.3 Screening factors and evaluation times ............................................................... 4

3.1.1.4 Parent and progeny ........................................................................................................ 5

3.1.2 Previous methodology ..................................................................................................... 5

3.1.2.1 An improved approach to "trigger values"........................................................... 5

3.1.2.2 Screening calculation curie inventory................................................................... 6

3.1.3 Current methodology ....................................................................................................... 6

3.1.3.1 Decay chains ........................................................................................................... 7

3.1.3.2 Half lives ................................................................................................................... 7

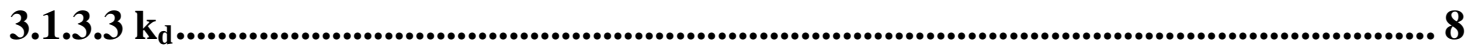

3.2 Coding................................................................................................................................ 9

3.2.1 Groundwater Coding ............................................................................................... 9

3.2.1.1 Initialization ............................................................................................... 9

3.2.1.2 Calculations ............................................................................................................. 12

3.2.1.3 Output .............................................................................................................................. 12

3.2.2 Input forms ....................................................................................................................... 13

3.2.3 Modifications to Intruder Analysis............................................................................. 14

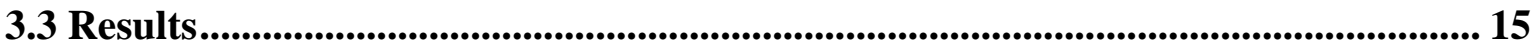

3.3.1 Comparison with previous results ................................................................................. 15

3.3.1.1 Without daughters .......................................................................................................... 15

3.3.1.2 With daughters.................................................................................................... 16

3.3.2 Comparison with NCRP .......................................................................................... 18

3.3.3 Daughters with their leach rates................................................................................ 19

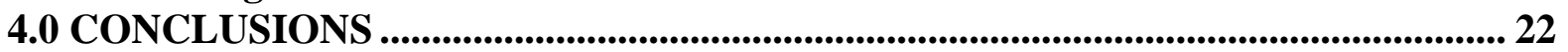

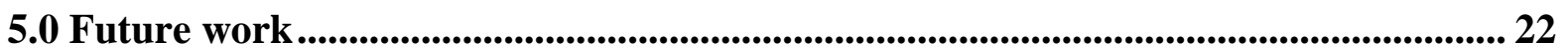

5.1 “Transient” Calculation....................................................................................... 22

5.2 Infiltration rate ................................................................................................................ 22

5.3 Half life consistency .......................................................................................................... 23

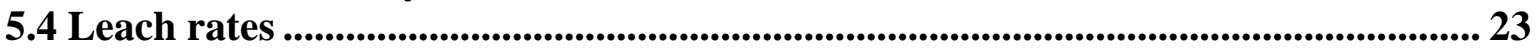

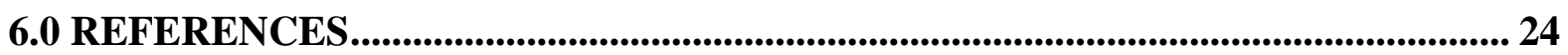

Appendix A. Design Check Instructions for Automated Groundwater Screening ........ 25

Appendix B. Reviewer Comments.......................................................................................... 31

Appendix C. WITS email ....................................................................................................... 35 


\section{LIST OF FIGURES}

Figure 3-1 Flowchart of Groundwater Screening Coding .............................................. 10

Figure 3-2 Flowchart of Groundwater Screening Coding (continued) ............................. 11

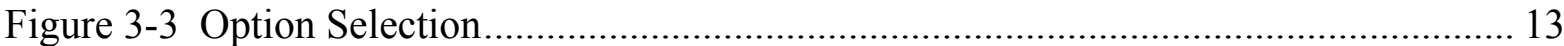

Figure 3-4 GroundWater Options ............................................................................. 14

Figure 3-5 GroundWater Screening Parameters ....................................................... 14

\section{LIST OF TABLES}

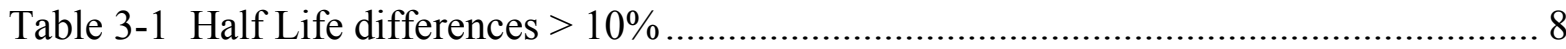

Table 3-2 Comparison of Groundwater calculation with Ref. R. 6-3 …............................ 16

Table 3-3 Comparison of Previous Analyses with Automated Screening........................... 17

Table 3-4 Daughters with their leach rates .................................................................. 20

Table 3-5 Comparison of dose $\left(\mathrm{mrem} / 10^{7} \mathrm{Ci}\right)$ for three calculational methods .................... 22 


\section{LIST OF ACRONYMS}

CDP Cellulose Degradation Product

NCRP National Council on Radiation Protection and Measurements

SFGW Screening Factor for Ground Water

SRNL Savannah River National Laboratory

SRS Savannah River Site 


\subsection{EXECUTIVE SUMMARY}

The Automated Intruder Analysis has been extended to include an Automated Ground Water Screening option. This option screens 825 radionuclides while rigorously applying the National Council on Radiation Protection (NCRP) methodology. An extension to that methodology is presented to give a more realistic screening factor for those radionuclides which have significant daughters. The extension has the promise of reducing the number of radionuclides which must be tracked by the customer. By combining the Automated Intruder Analysis with the Automated Groundwater Screening a consistent set of assumptions and databases is used. A method is proposed to eliminate trigger values by performing rigorous calculation of the screening factor thereby reducing the number of radionuclides sent to further analysis.

Using the same problem definitions as in previous groundwater screenings, the automated groundwater screening found one additional nuclide, Ge-68, which failed the screening. It also found that 18 of the 57 radionuclides contained in NCRP Table 3.1 failed the screening. 


\subsection{INTRODUCTION}

This report describes the automated groundwater screening computer application. This application was developed to complement the automated intruder analysis (R. 6-1). These applications have been combined into a single application which allows the analyst to perform either groundwater screening or intruder analysis while using common databases and assumptions. This will provide a consistency in calculational methods which may have been missing in the past. The automated system provides a menu driven input and writes its results to Microsoft Word and Excel files.

\subsection{METHODOLOGY}

\subsection{DISCUSSION}

Following is a brief discussion of the NCRP methods, the past methodology used for the groundwater screening and the current methodology. The current methodology is a rigorous application of the methods described in NCRP (Ref. R. 6-2). Discussions of previous analyses vis-à-vis the NCRP are also included.

To alleviate any confusion, in this report the term "failed screening" means that the radionuclide in question exceeds the screening limit.

\subsubsection{NCRP methodology}

This section includes explanations of the NCRP method because in many cases the NCRP leaves much to the reader and in other cases their approach may be open to question. The additional explanations also serve to improve the interpretation of the NCRP approach and to clarify the SRNL approach.

\subsubsection{Initial inventory}

The NCRP considers two cases for initial inventories involving multiple disposals over time. First, if there are no significant radioactive progeny, then each disposal is individually decayed from the time of disposal to the starting time for the analysis. Second, if there are significant radioactive progeny, then the inventory is not decayed to the starting time for the analysis. These approaches are shown in Fig. 3.1 of Vol. 1 (R. 6-2) and are described by the two quotations below.

Page 43, Vol. 1 "The source-term inventory of radionuclides with no significant radioactive progeny at the start of the dose calculations is estimated by summing all previous burials, adjusting for radioactive decay." [emphasis added]

Page 43, Vol. 1 "In the case of radionuclides which have significant radioactive progeny, it is not as simple to account for radioactive decay because the radioactivity 
of the buried waste might increase with time rather than decrease. For these radionuclides, the source-term inventory of parent radionuclides is calculated conservatively by summing all burials irrespective of when they occurred." [emphasis added]

The second approach is somewhat inaccurate. The parents should be decayed and the progeny that grow in during this time period should be considered. The NCRP approach is an approximation that is conservative for the parent, but may be non-conservative overall. The SRS screening considers a single disposal, thus there is no decay from the time of disposal to the starting time for the analysis and the potential non-conservatism cannot develop.

Table 3.1 of R. 6-2 lists the radionuclides with significant long-lived daughters that will determine which of the two approaches to adopt. Table 3.1 lists Am-227, which is not part of the 825 radionuclides. It is unclear whether the radionuclide in error should be Am-237, Ac227 or some other radionuclide. Regardless, Table 3.1 has no effect on the SRS screening, because the SRS screening considers a single disposal. Thus there is no decay from the time of disposal to the starting time of the analysis.

\subsubsection{Leach rate}

The leach rate is merely the rate of contaminant movement divided by the thickness of the contaminated zone. Further the rate of contaminant movement is the rate of water movement divided by a retardation factor.

The NCRP equation for the leach rate (page 43) is

$$
\lambda_{L}=\frac{I}{R H n}
$$

\section{Equation 1}

where $\lambda_{\mathrm{L}}$ is the leach rate $(1 / \mathrm{yr})$

I is the infiltration rate $(\mathrm{m} / \mathrm{yr})$

$\mathrm{R}$ is the retardation coefficient (dimensionless)

$\mathrm{H}$ is the thickness of the layer of buried soil (m) (see discussion in section 3.3.2)

$\mathrm{n}$ is the porosity of the soil (dimensionless).

The leach rate should use the pore velocity of the water, which is $I / \Theta$, where $I$ is the infiltration rate and $\Theta$ is the volumetric moisture content $\left(\mathrm{m}^{3} / \mathrm{m}^{3}\right)$. The NCRP assumes that the sediments are saturated because the equation used the porosity $n$, where $\Theta=S$, where $S$ is the saturation (at full saturation $S=1$ ). This gives the volumetric water content that the radionuclides can travel through.

The NCRP equation for the retardation coefficient is

$$
R=1+\frac{\rho k_{d}}{n}
$$

\section{Equation 2}


where $\rho$ is the density of soil (dry bulk density) $\left(\mathrm{kg} / \mathrm{m}^{3}\right)$

$\mathrm{k}_{\mathrm{d}}$ is the soil partition coefficient $\left(\mathrm{m}^{3} / \mathrm{kg}\right)$

and $\mathrm{n}$ is the porosity (dimensionless).

In Equation 2 the denominator should be multiplied by the saturation which is equivalent to replacing the denominator by $\Theta$. Thus the NCRP has consistently assumed that the sediments are saturated.

These two errors partially offset each other when calculating $\lambda_{\mathrm{L}}$ because the first error effectively decreases the infiltration rate in the numerator $(\mathrm{I} / \mathrm{n})$, and the second error decreases the retardation coefficient in the denominator. At high $\mathrm{k}_{d} \mathrm{~s}$, the effect of the errors should be insignificant.

The NCRP also applies the parent leach rate to all the progeny as shown by the following quote

Page 44, Vol 1 "The leach rate of all progeny in a chain decay are assumed to be the same as the first member of the chain."

This is inaccurate, and can become very important when any significant progeny has a $\mathrm{k}_{\mathrm{d}}$ that is appreciably lower than the $\mathrm{k}_{\mathrm{d}}$ of the parent.

The NCRP apparently has provided the incorrect units for the $\mathrm{k}_{d} \mathrm{~S}$ in Table 4.1. The units are shown as $\mathrm{m}^{3} \mathrm{~kg}^{-1}$, but they should be $\mathrm{ml} \mathrm{g}^{-1}$.

\subsubsection{Screening factors and evaluation times}

The screening factors should be established based on the peak doses that occur at any time after institutional control ends to the final time of compliance. The NCRP states

Page 45, Vol 1 "Screening dose factors are evaluated using the models discussed in Sections 4.2.2 and 4.2.3 evaluated at a range of times from 2 to $1,000 \mathrm{y}$, and the largest dose is utilized in evaluating compliance and requirements." (emphasis added)

Page 45, Vol 1 "The model evaluated at $2 \mathrm{y}$ assumes administrative control over the site, and therefore includes only doses from the groundwater drinking pathway." "The model evaluations from 10 to 1,000 y consider all pathways."

The NCRP has selected a variety of times encompassing the time period of interest $(2,10$, $30,100,300$ and 1000 y from page 220, Vol. 1). This approach has merit by sampling across the entire time range. This scheme does not necessarily find the maximum so an improvement would be to do the calculation for every year and report the years' maximum. Unfortunately, the NCRP does not report the year that produced their screening factor. 


\subsubsection{Parent and progeny}

The NCRP includes the dose generated by the parent radionuclide and all progeny as stated below:

Page 46, Vol. 1 "The effective screening value for radionuclide is calculated by summing the contributions from the parent and all progeny."

The NCRP reports screening factors in Table D.1 for each chain.

Page 220, Vol. 2, "Separate factors are given for the parent radionuclide and each daughter nuclide contributing more than 10 percent of that of the parent." "The last factor in each nuclide family (shown in bold) shows the total. This is the number listed in Table 3.2 in Volume II for the Level I ground screening factors."

A couple of interesting examples in Table D.1 are as follows:

1. Am-241 shows no progeny (no Np-237) and the total screening factor is the same as the Am-241 screening factor

2. U-234 shows no progeny but the total screening factor is larger than the U-234 screening factor

The first example indicates that the maximum time for screening may be important. If the maximum time were higher than 10 half lives of Am-241, about 4,000 years, then essentially all the Am-241 would be decayed and only Np-237 would remain. Thus the screening results are only applicable over the time frame that is analyzed.

The second example shows that all the progeny must be considered even though no individual progeny contributes $10 \%$ or more.

\subsubsection{Previous methodology}

The previous methodology was a modification to the NCRP (Ref. R. 6-2) methods. A detailed description of the methods is described in Cook (R. 6-3). In Cook (R. 6-3) the screening factor was calculated as a function of the parent radionuclide only, i.e.,

$$
S F_{G W}=\lambda_{L} A_{0} \frac{U_{D W}}{V} X_{0} D F_{i n g}
$$

Equation 3

where the subscript " 0 " denotes parent. In fact, as will be shown below, the $\mathrm{X}_{0}$ term should be a summation of the factors from the daughter radionuclides.

\subsubsection{An improved approach to "trigger values"}

The "Trigger Values" calculated for radionuclides with significant daughters were based on the screening factors developed in NCRP (R. 6-2). There are numerous differences with assumptions used in the analyses between Cook (R. 6-3) and NCRP which cause the trigger 
values in Ref. R. 6-3 to be extremely conservative. By a rigorous application of the NCRP methods some of the significant daughters may not fail the screen.

The Radioactive Waste Management Basis (RWMB) contains a list of limits and the documents that developed those limits. "Trigger values" are merely $1 / 100^{\text {th }}$ of the value of a limit developed from a screening analysis. The "trigger values" could be replaced by the screening limit.

One benefit would be that Solid Waste would not have to separately keep track of the inventories vs. their "trigger values." Another benefit would be that even if the "trigger value" is exceeded, no action would be triggered. If an action were triggered, the likely response would be to apply the screening limit anyway, thus this approach reduces the effort and complexity of the process.

\subsubsection{Screening calculation curie inventory}

The screening analysis introduces a 10 million $\mathrm{Ci}$ inventory for each radionuclide. However, no basis or reference is provided for this value. A recent check of WITS (see Appendix C) indicates that about 5.0379 million $\mathrm{Ci}$ total are in the E-Area for those radionuclides that survived the screening.

\subsubsection{Current methodology}

The current application is a rigorous application of the methods described in NCRP. The screening factor is given by

$$
S F_{G W}=\lambda_{L} A_{0} \frac{U_{D W}}{V} \sum_{i=1}^{n} X_{i}\left(D F_{i n g}\right)_{i}
$$

Equation 4

where

$\mathrm{SF}_{\mathrm{GW}}=$ screening factor $\left(\mathrm{Sv} /\left[\mathrm{Bq} / \mathrm{m}^{3}\right]\right)$

$\lambda_{\mathrm{L}}=$ parent leach rate $(1 / \mathrm{yr})$

$\mathrm{A}_{0}=e^{-\left(\lambda_{0}^{r} R T_{\text {travel }}\right)}=$ fraction of parent decayed during transport (dimensionless)

$\mathrm{T}_{\text {travel }}=$ time for radionuclide to travel to water table $(\mathrm{y})$

$\mathrm{U}_{\mathrm{DW}}=$ water consumption $(\mathrm{L} / \mathrm{yr})$

$\mathrm{V}=$ dilution volume $(\mathrm{L} / \mathrm{yr})$

$\mathrm{DF}_{\text {ing }}=$ ingestion dose factor $(\mathrm{Sv} / \mathrm{Bq})$

$\mathrm{N}=$ number of progeny

$$
X_{i}=\frac{1}{T_{a v}}\left[\prod_{j=1}^{k} \lambda_{i}^{r} f_{j}\right] \sum_{h=0}^{N} \frac{e^{-\lambda_{n}^{r} t_{\text {delay }}}\left(1-e^{-\lambda_{n}^{r} T_{A V}}\right)}{\lambda_{n}^{r} \prod_{p=0}^{k}\left(\lambda_{p}^{r}-\lambda_{h}^{r}\right)} \text { for } \mathrm{p} \neq \mathrm{h}
$$

Equation 5 
where

$\lambda^{\mathrm{r}}=$ radioactive decay constant $(1 / \mathrm{yr})$

$\mathrm{f}_{\mathrm{j}}=$ decay (or branching) fraction for daughter $\mathrm{j}$, (unitless)

$\mathrm{T}_{\mathrm{av}}=$ averaging time, typically 1 year

$t_{\text {delay }}=$ delay time in release of parent radionuclide, (year)

subscript $\mathrm{i}=$ ith daughter, $0=$ parent, $\mathrm{p}$ and $\mathrm{h}=$ progeny indices

In words, $X_{\mathrm{i}}$ is the average fraction of progeny $i$ in terms of the inventory of the parent radionuclide over the same period. This calculation is not done explicitly in the new coding written for the groundwater screening but using the methods already developed for the Intruder Analysis.

In addition to a rigorous application of the NCRP methodology an additional calculation is performed which is an adaptation of Equation 4. Equation 4 is based upon the leach factor $\left(\lambda_{\mathrm{L}}\right)$ of the parent. In cases where the parent leach rate is low the parent may not fail the screening even though the leach rate of a daughter is high. For example, when using Equation $4 \mathrm{Pu}-241$ does not show up as failing the screening even though its daughter, $\mathrm{Np}$ 237 , does. This seems to be one of the primary reasons for Table 3.1 of NCRP. The modification treats the summation operator in Equation 4 as the linear operator it is and rearranges terms so that it calculates

$$
S F_{G W}=\frac{U_{D W}}{V} \sum_{i=1}^{n} \lambda_{i} A_{i} X_{i} D F_{i n g}
$$

Equation 6

Equation 6 allows the contribution of all the daughters to be accounted for more accurately. The ramifications of this calculation will be discussed in the Section 3.3.3.

\subsubsection{Decay chains}

In order to calculate the screening factors using Equation 4 the entire decay chain of a parent is required. The intruder analysis looked at about 180 radionuclides while this screening analysis requires 825 radionuclides. The chains were obtained by using the Chains computer code (R. 6-4). Chains was also used to generate the decay chains for the intruder analysis. A Perl (a computer language) script was written to run the Chains for the 825 radionuclides and extract the needed data. This data was added to the existing decay chain table in the intruder analysis. It should be noted that to be consistent with the Intruder Analysis only the two greatest branching fractions are used. There are few cases in which there is a third branch and all those cases had very small fractions (on the order of $10^{-5}$ or less). The branching fractions used in all cases are those from Eckerman (Ref. R. 6-4).

\subsubsection{Half lives}


There is a plethora of half life data. Because it is not always clear what data are being used, or should be used, the screening analysis is written to allow the user to select what half life data set to use. The data sets included are Cook's (R. 6-3), Eckerman (R. 6-4), and Wallet Card (R. 6-5). Table 3-1 shows those radionuclides for which the half lives differ by more than $10 \%$. The table values are years.

\begin{tabular}{|c|c|c|c|c|c|c|c|}
\hline & Eckerman & Wallet & Cook & & Eckerman & Wallet & Cook \\
\hline $\mathrm{Ag}-102$ & 2.4527E-05 & 2.4527E-05 & 2.8519E-05 & $\mathrm{Pb}-202$ & $3.0000 E+05$ & $5.2500 \mathrm{E}+04$ & $3.0000 \mathrm{E}+05$ \\
\hline $\mathrm{Ag}-104 \mathrm{~m}$ & 6.3693E-05 & 6.3693E-05 & 5.7039E-05 & Po-212 & 9.6649E-09 & 9.4747E-15 & $9.6649 \mathrm{E}-15$ \\
\hline $\mathrm{Ag}-108 \mathrm{~m}$ & $1.2700 \mathrm{E}+02$ & 4.1800E+02 & $1.3000 \mathrm{E}+02$ & Po-213 & $1.3309 \mathrm{E}-07$ & 1.1566E-13 & $1.3309 \mathrm{E}-13$ \\
\hline At-215 & 3.1688E-12 & $3.1688 \mathrm{E}-12$ & 1.9013E-07 & Po-214 & 5.2064E-06 & 5.2064E-12 & $5.2064 \mathrm{E}-12$ \\
\hline At-216 & 9.5064E-12 & $9.5064 \mathrm{E}-12$ & 5.7039E-07 & Re-187 & $5.0000 \mathrm{E}+10$ & $4.3500 \mathrm{E}+10$ & $5.0000 \mathrm{E}+10$ \\
\hline At-218 & 6.3376E-08 & 4.7532E-08 & 6.3376E-08 & Rh-102 & $2.9000 \mathrm{E}+00$ & $2.0700 \mathrm{E}+02$ & $2.9000 \mathrm{E}+00$ \\
\hline $\mathrm{Au}-193$ & $2.0135 \mathrm{E}-03$ & $2.0135 \mathrm{E}-03$ & $1.7650 \mathrm{E}+01$ & $\mathrm{Rh}-102 \mathrm{~m}$ & 5.6674E-01 & 7.9398E-03 & $5.6674 \mathrm{E}-01$ \\
\hline $\mathrm{Bi}-207$ & $3.8000 \mathrm{E}+01$ & $3.1550 \mathrm{E}+01$ & $3.8000 \mathrm{E}+01$ & $\mathrm{Rn}-218$ & 1.1091E-09 & 1.1091E-09 & $6.6545 \mathrm{E}-05$ \\
\hline $\mathrm{Br}-74 \mathrm{~m}$ & 7.8903E-05 & 8.7459E-05 & 7.8903E-05 & Se-79 & $6.5000 \mathrm{E}+04$ & $1.1000 \mathrm{E}+06$ & $6.5000 \mathrm{E}+04$ \\
\hline $\mathrm{Ca}-41$ & $1.4000 \mathrm{E}+05$ & $1.0300 \mathrm{E}+05$ & $1.4000 \mathrm{E}+05$ & Si-32 & $4.5000 \mathrm{E}+02$ & $1.7200 \mathrm{E}+02$ & $4.5000 \mathrm{E}+02$ \\
\hline Cd-113 & $9.3000 \mathrm{E}+15$ & $7.7000 \mathrm{E}+15$ & $9.3000 \mathrm{E}+15$ & 31 & $3 \mathrm{E}-05$ & 4.2399E-05 & 4.8483E-05 \\
\hline $\mathrm{Cm}-250$ & $6.9000 \mathrm{E}+03$ & $9.7000 \mathrm{E}+03$ & $6.9000 \mathrm{E}+03$ & Ta-173 & 4.1638E-04 & 3.5820E-04 & 4.2209E-04 \\
\hline $\mathrm{Fe}-60$ & $1.0000 \mathrm{E}+05$ & $1.5000 \mathrm{E}+06$ & $1.0000 \mathrm{E}+05$ & Ta-180 & $1.0000 \mathrm{E}+13$ & $1.2000 \mathrm{E}+15$ & $1.0000 \mathrm{E}+13$ \\
\hline Fm-252 & 2.5896E-03 & 2.8964E-03 & 2.6238E-03 & Tb-156 & 1.4620E-02 & 1.4648E-02 & $2.7835 \mathrm{E}-03$ \\
\hline Fr-219 & $6.6545 \mathrm{E}-10$ & $6.3376 \mathrm{E}-10$ & 3.9927E-05 & Tb-156m & $2.7835 \mathrm{E}-03$ & $2.7835 \mathrm{E}-03$ & $5.7039 \mathrm{E}-04$ \\
\hline Gd-148 & $9.3000 \mathrm{E}+01$ & $7.4600 \mathrm{E}+01$ & $9.3000 \mathrm{E}+01$ & Tb-156n & 5.7039E-04 & 6.0461E-04 & $1.5000 \mathrm{E}+02$ \\
\hline $\mathrm{Hg}-194$ & $2.6000 \mathrm{E}+02$ & $4.4400 \mathrm{E}+02$ & $2.6000 \mathrm{E}+02$ & Tb-157 & $1.5000 \mathrm{E}+02$ & $7.1000 \mathrm{E}+01$ & $1.5000 \mathrm{E}+02$ \\
\hline In-115 & $5.1000 \mathrm{E}+15$ & $4.4100 \mathrm{E}+14$ & $5.1000 \mathrm{E}+15$ & Tb-158 & $1.5000 \mathrm{E}+02$ & $1.8000 \mathrm{E}+02$ & $1.9822 \mathrm{E}-01$ \\
\hline $\mathrm{K}-45$ & 3.8026E-05 & 3.2892E-05 & 3.8026E-05 & Tb-160 & 1.9795E-01 & 1.9795E-01 & $1.8919 \mathrm{E}-02$ \\
\hline La-138 & $1.3500 \mathrm{E}+11$ & $1.0500 \mathrm{E}+11$ & $1.3500 \mathrm{E}+11$ & Tb-161 & 1.8919E-02 & 1.8836E-02 & 1.4620E-02 \\
\hline Mo-93 & $3.5000 \mathrm{E}+03$ & 4.0000E+03 & $3.5000 \mathrm{E}+03$ & Tc-97 & $2.6000 \mathrm{E}+06$ & $4.2100 \mathrm{E}+06$ & $2.6000 \mathrm{E}+06$ \\
\hline $\mathrm{Nb}-93 \mathrm{~m}$ & $1.3600 \mathrm{E}+01$ & $1.6130 \mathrm{E}+01$ & $1.3600 \mathrm{E}+01$ & Te-121 & 4.6543E-02 & 5.2457E-02 & 4.6543E-02 \\
\hline $\mathrm{Nb}-98$ & 9.7916E-05 & 5.4377E-06 & 9.7916E-05 & Te-123 & $1.0000 \mathrm{E}+13$ & $6.0000 \mathrm{E}+14$ & $1.0000 \mathrm{E}+12$ \\
\hline $\mathrm{Np}-236 \mathrm{a}$ & $1.1500 \mathrm{E}+05$ & $1.5400 \mathrm{E}+05$ & $1.1500 \mathrm{E}+05$ & Ti-44 & $4.7300 \mathrm{E}+01$ & $6.0000 \mathrm{E}+01$ & $4.7300 \mathrm{E}+01$ \\
\hline Os-191 & 4.2163E-02 & 4.2163E-02 & $1.4830 \mathrm{E}-03$ & Xe-129m & 2.1903E-02 & 2.4312E-02 & 2.1903E-02 \\
\hline Os-191m & 1.4864E-03 & 1.4944E-03 & 4.2163E-02 & & & & \\
\hline
\end{tabular}

Table 3-1 Half Life differences $>10 \%$

\subsubsection{3 $\boldsymbol{k}_{d}$}

The $\mathrm{k}_{\mathrm{d}}$ 's used are those by Cook (R. 6-3). They are a combination of NCRP values supplemented by SRS experimentally determined values for certain radionuclides. No 
reduction in the $\mathrm{k}_{\mathrm{d}}$ 's were introduced for cellulose degradation products (CDPs). Thus the selected $\mathrm{k}_{\mathrm{d}}$ 's may be non-conservative for all disposal units affected by CDPs.

\subsection{CODING}

The automated groundwater screening is an application written in Visual Basic (VB). The application is menu driven and seamlessly meshed with the automated intruder analysis. The coding was written to take advantage of as much of the intruder coding as possible without affecting it. The following sections describe the new groundwater screening coding, modifications to the intruder coding, and the menus used to run the screening.

\subsubsection{Groundwater Coding}

\subsubsection{Initialization}

The initialization for the groundwater screening followed the philosophy established by the intruder analysis. The problem specific parameters are entered on forms while the underlying data are contained in Excel worksheets. The problem specific parameters will be discussed in Section 3.2.2.

When the groundwater screening is selected, the VB program automatically loads all the required data via a subroutine called form_load. This subroutine calls an Excel workbook, GroundwaterInput.xls, which contains the appropriate data. This workbook contains three worksheets which are called in turn to load the data. Worksheet " $\mathrm{Kd}$ " contains the $\mathrm{k}_{\mathrm{d}} \mathrm{s}$, decay constants, and dose factors. Worksheet "Parameter Values" contains the default values used in the generation of the groundwater scenario form. Worksheet "SigDaughters" is a listing of the radionuclides which appear in Table 3-1 of NCRP (R. 6-2).

The groundwater form_load calls frmScenario from the intruder side which forces the intruder form_load to execute. This is necessary so that the decay information is loaded.

Figure 3-1 is a high level flowchart of the groundwater screening coding. 


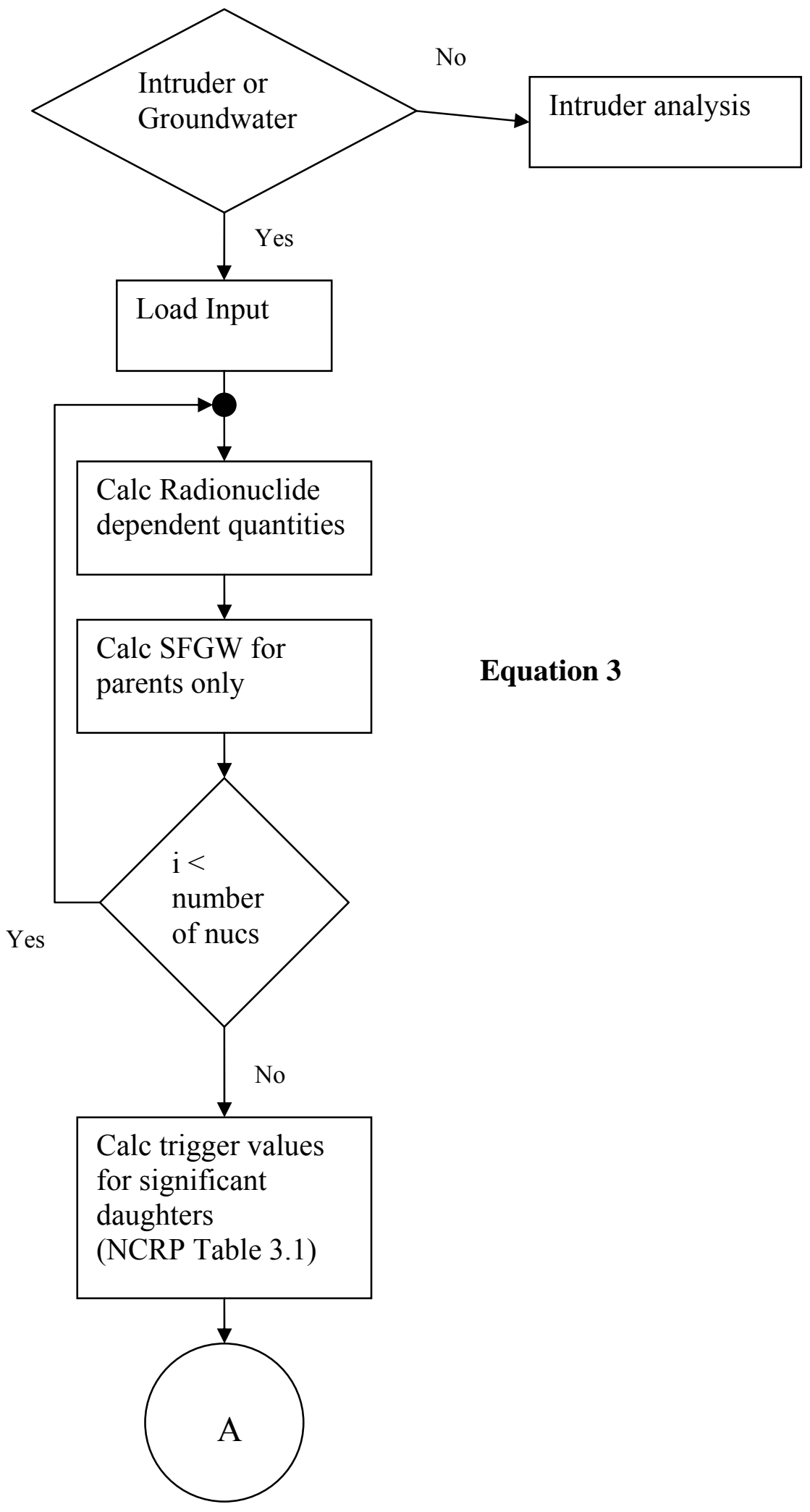

Figure 3-1 Flowchart of Groundwater Screening Coding 


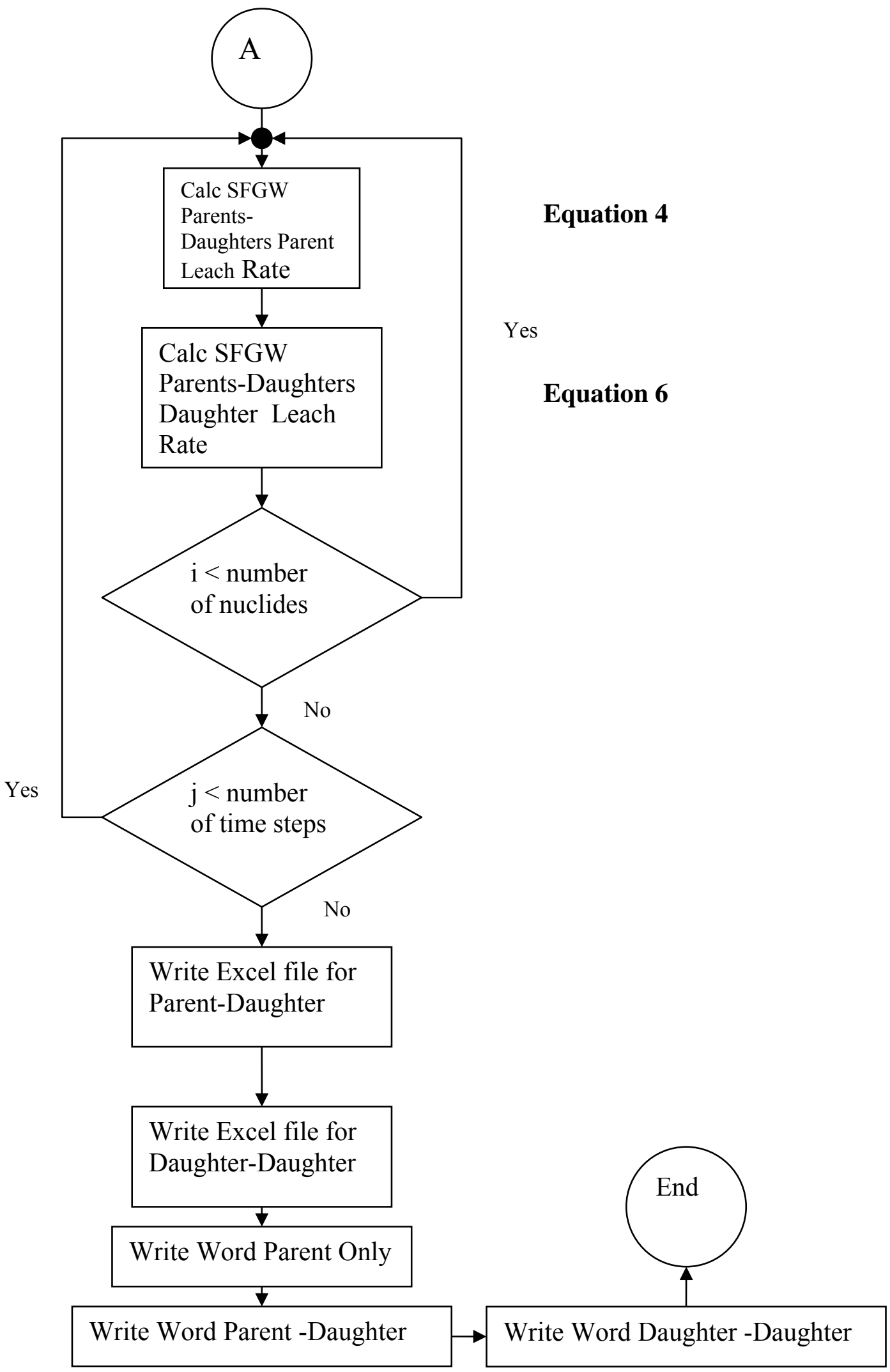

Figure 3-2 Flowchart of Groundwater Screening Coding (continued) 


\subsubsection{Calculations}

The calculations briefly described below are those which compute the screening values and determine which radionuclides fail the screen. The four calculations are: 1) current SRS screening values; 2) current SRS trigger values; 3) screening values for parents' leach rates with complete decay chains; 4) screening values using daughter leach rates with complete decay chains.

Subroutine RunScreening is the driver for the calculations. The calculational algorithm is quite simple. RunScreening performs the calculation described in Equation 3, i.e., parents only. This reproduces the previous SRS analysis.

A call is then made to ScreenSigDaughters. This routine runs the more rigorous implementation of the NCRP calculations. An outer loop is run in which seven time steps are evaluated. For each time step an inner loop runs for all radionuclides in the chain. Calls are made to the decay chain subroutines on the intruder side. Once the decay chain information is obtained screening factors described by Equation 4 (daughters with parent leach rate) and Equation 6 (daughters with daughter leach rates) are calculated.

Calls are then made to output subroutines which write the Word and Excel tables. The output calls need to be in the order in which they appear as some post-processing information calculated in one routine is passed to another. The output routines calling sequence is WriteParentScreeningTable2, WriteParentScreeningTable3, WriteParentScreeningTable, WriteParentDaughterScreeningTable, and WriteSigDaughterScreeningTable.

\subsubsection{Output}

The five output routines mentioned above combine to write one Word document and one Excel workbook. The user is prompted to specify names for file saves.

WriteParentScreeningTable2 and WriteParentScreeningTable3 are used to write the Excel workbook. WriteParentScreeningTable2 is used to write information for the calculation in which decay chains are used but where only the parent leach rate is used (Equation 4). The routine parses the screening factors to find at which time the maximum value is obtained for each radionuclide, calculates a dose based on the maximum value, and determines if the dose exceeds the imposed limit. It also writes the input definitions on its worksheet.

WriteParentScreeningTable3 writes the same data format as WriteParentScreeningTable2 but uses the values based on the daughter leach rates screening factors (Equation 6) to write to a second worksheet. It performs some additional work in that it looks for radionuclides which exceed the dose limit and do not appear on the previous worksheet based on the list of significant daughters in NCRP Table $3-1$. 
WriteParentScreeningTable and WriteParentDaughterScreeningTable are used to create the Word document tables. The Word document consists of three tables. The first, which is written by WriteParentScreeningTable, contains a list of the radionuclides which fail the screen along with their doses and trigger values for the calculation based on parents only (Equation 3). WriteParentDaughterScreeningTable writes the same table for the calculation based on using the complete decay chain and picking the maximum screening factor (Equation 4).

WriteSigDaughterScreeningTable writes a Word table based on NCRP Table 3-1. For each radionuclide in the table a trigger value is calculated. This trigger value is based on Cook ( $R$. 6-3). The problem with the trigger value is that it is inconsistent with assumptions used for the rest of the analysis. The screening factors used are those obtained from NCRP (R. 6-2). These screening factors are based on very different assumptions than used for SRS specific disposal. This was discussed in Section 3.1.2.1.

\subsubsection{Input forms}

The input for the groundwater screening is form driven. Following is a description of the forms used to input data and execute the screening.

When the executable is double clicked the first menu to appear is the options menu (Figure 3-3). The desired option is selected and the "Run Selection" button is clicked to execute the program. If the Intruder Analysis is selected, than the standard Intruder analysis is run.

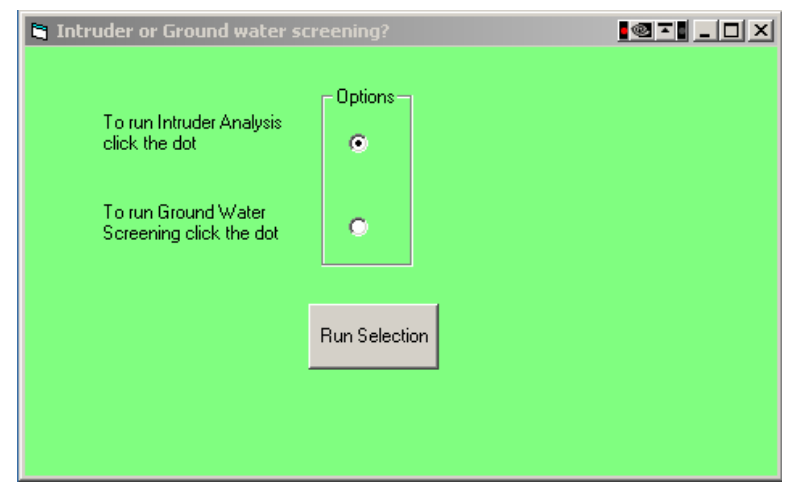

Figure 3-3 Option Selection

If the ground water screening is selected, several more options appear (Figure 3-4). Two options are given for the nuclide list. It is strongly recommended that the "Long" option be selected. This runs through the entire list of 825 radionuclides. The "Short" list is created from previous screenings and contains about 180 radionuclides.

Three options are available for half lives. The "Wallet Card" option uses half lives from Ref. R. 6-5. The "Eckerman" option uses half lives generated by Ref. R. 6-4. The "Cook's" option uses half lives used for previous screenings as defined in Ref .R. 6-3. 


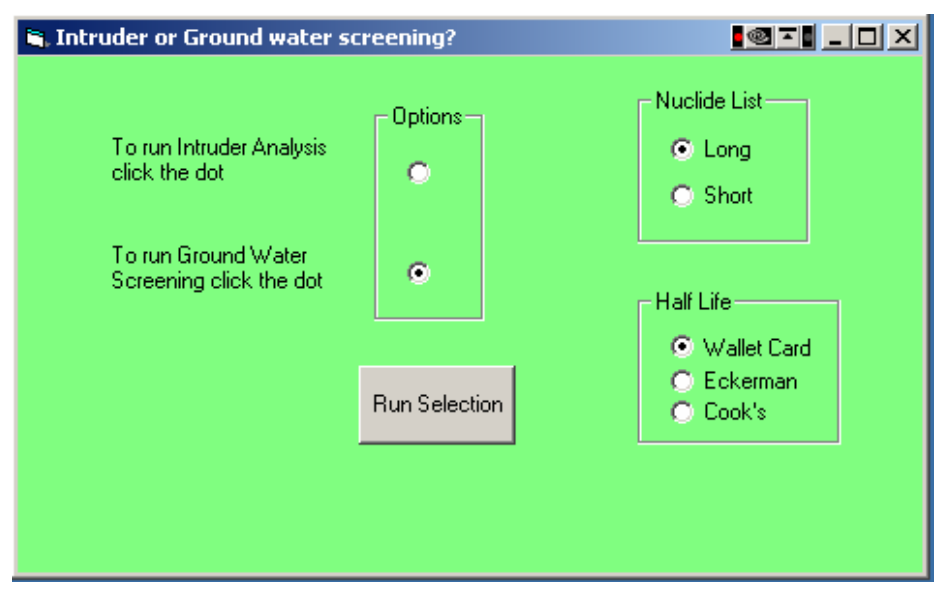

Figure 3-4 GroundWater Options

After the "Run Selection" button is clicked the "GroundWater Screening" menu (Figure 3-5) appears. On the left side there is a scrollable list of all radionuclides available, based on the selection from the previous menu (either the "Long" or "Short" list). The "Select All" should be used. The right side of the menu allows the user to modify any of the constants used in the calculations. Default values are loaded in, based on Ref. R. 6-3, and are also shown parenthetically in the field descriptors. Once these constants are set the screening is executed by clicking the "Run Screening" button.

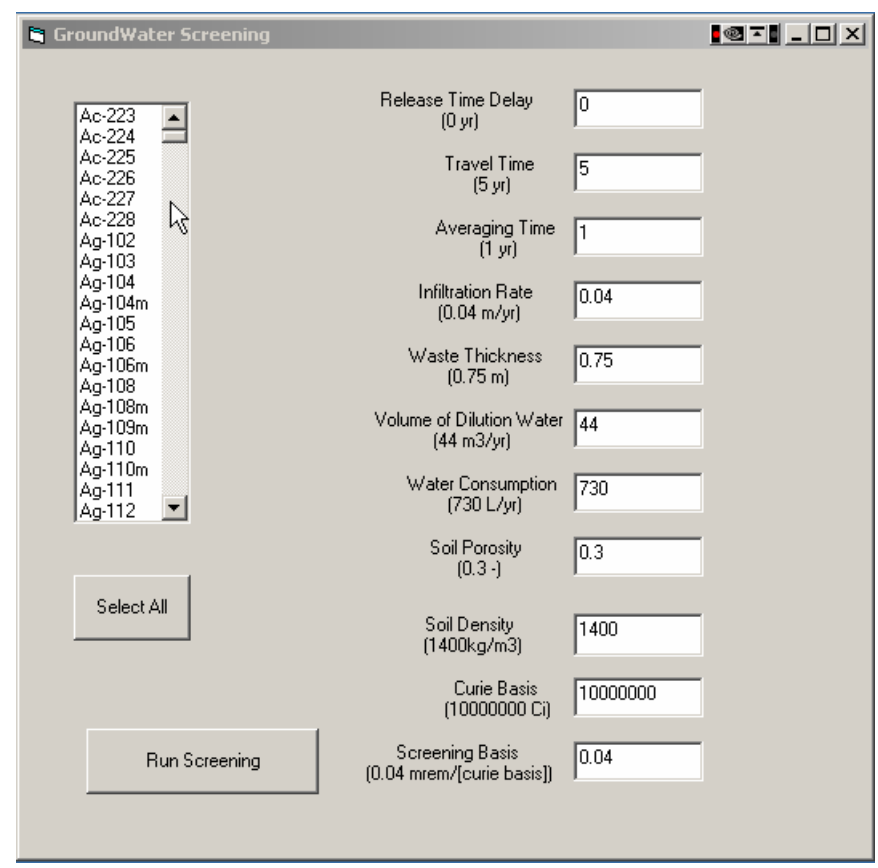

Figure 3-5 GroundWater Screening Parameters

\subsubsection{Modifications to Intruder Analysis}


Changes to the Intruder Analysis were kept to an absolute minimum and are transparent if one runs the Intruder Analysis. The major change was the renaming and addition of worksheets to the IntruderInput.xls file. The file called by the program is now called IntruderInputLong.xls. Worksheets were renamed and added based on the "Long" and "Short" options. The previously existing worksheets were renamed with the suffix "Short". Worksheets of the same format but including all 825 radionuclides were added, maintaining the same prefix and the suffix "Long".

There were some temporary arrays in the decay chain calculation routines which were hard dimensioned for the smaller arrays of the "Short" option. These dimensions were hard coded to a larger value to accommodate the larger arrays of the "Long" option.

In frmScenario's load_form subroutine some of the input processing for the intruder analysis is bypassed if the groundwater option is selected. The bypassed input processing is routines not used by the groundwater screening and bypassing them speeds up the loading of the databases used by the screening.

\subsection{RESULTS}

\subsubsection{Comparison with previous results}

\subsubsection{Without daughters}

The first step in assessing the automated groundwater screening was to see if the results of previous analyses could be duplicated. This means duplicating a run based solely on parents, i.e., no decay chains. A comparison of the first part of the table can be seen in Table 3-2. The results match quite well. Note that the Word tables only carry as many significant figures as is specified in the cell format. If three significant figures are specified only three are kept, unlike Excel where the displayed value and the actual value of the cell are not the same because the actual cell value is all digits contained in a double precision number. 


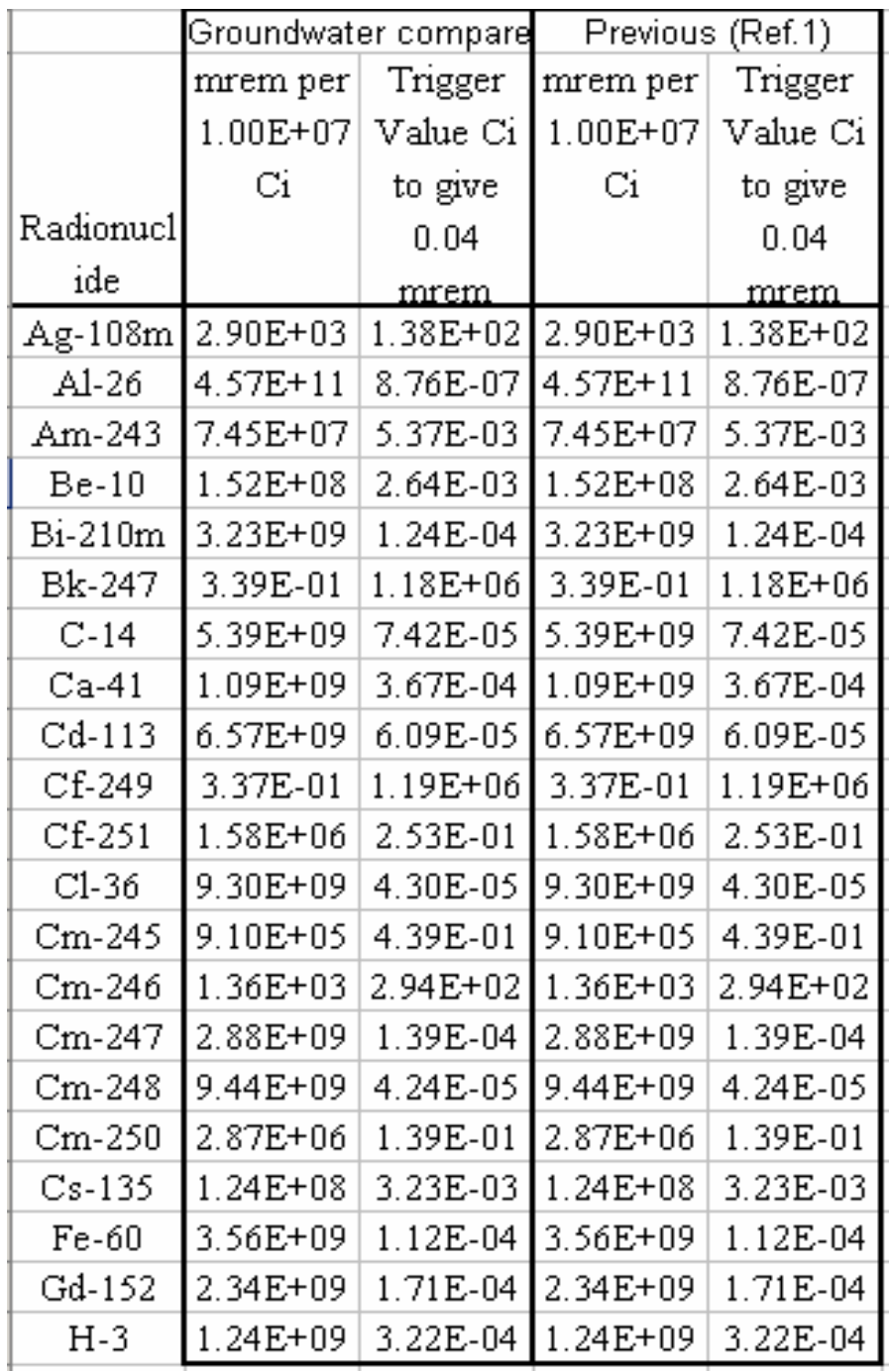

Table 3-2 Comparison of Groundwater calculation with Ref. R. 6-3

\subsubsection{With daughters}

Table 3-3 shows a comparison of the previous analysis with the rigorous groundwater implementation. The previous analysis was predicated upon only parents and at a single time period of 0 years delay. The rigorous implementation is run at delays of $2,10,30,100,300$, and 1000 years (as per Ref. R. 6-2) along with a time of the user's choice. It also includes the complete decay chain. The screening factor used to determine the dose is selected to be the maximum value from any of the time periods.

The last column of Table 3-3 shows the percent difference (if the difference was greater than $10 \%$ ) between the previous analysis and this analysis. Nineteen radionuclides had a greater than $10 \%$ difference, with the greatest difference being $1238 \%$. One additional radionuclide, Ge-68, failed the screening. This demonstrates that a more rigorous implementation of the NCRP method gives more conservative screening. 
WSRC-TR-2005-00203, REVISION 0

\begin{tabular}{|c|c|c|c|c|c|c|}
\hline \multicolumn{3}{|c|}{ Ref. 2} & \multicolumn{3}{|c|}{ Automated GW } & \multirow[b]{2}{*}{$\begin{array}{l}\% \\
\text { difference }\end{array}$} \\
\hline Radionuclide & $\begin{array}{c}\text { mrem per } \\
1.00 \mathrm{E}+07 \\
\mathrm{Ci}\end{array}$ & $\begin{array}{c}\text { Trigger } \\
\text { Value Ci } \\
\text { to give } \\
0.04 \\
\text { mrem } \\
\end{array}$ & Radionuclide & $\begin{array}{c}\text { mrem per } \\
1.00 \mathrm{E}+07 \\
\mathrm{Ci}\end{array}$ & $\begin{array}{c}\text { Trigger } \\
\text { Value Ci } \\
\text { to give } \\
0.04 \\
\text { mrem } \\
\end{array}$ & \\
\hline Ag-108m & $2.90 \mathrm{E}+03$ & $1.38 \mathrm{E}+02$ & Ag-108m & $2.91 \mathrm{E}+03$ & $1.37 \mathrm{E}+02$ & \\
\hline Al-26 & $4.57 \mathrm{E}+11$ & $8.76 \mathrm{E}-07$ & Al-26 & $4.98 \mathrm{E}+11$ & $8.03 \mathrm{E}-07$ & \\
\hline Am-243 & $7.45 \mathrm{E}+07$ & $5.37 \mathrm{E}-03$ & Am-243 & $7.47 \mathrm{E}+07$ & $5.36 \mathrm{E}-03$ & \\
\hline $\mathrm{Be}-10$ & $1.52 \mathrm{E}+08$ & $2.64 \mathrm{E}-03$ & $\mathrm{Be}-10$ & $1.52 \mathrm{E}+08$ & $2.64 \mathrm{E}-03$ & \\
\hline $\mathrm{Bi}-210 \mathrm{~m}$ & $3.23 \mathrm{E}+09$ & $1.24 \mathrm{E}-04$ & $\mathrm{Bi}-210 \mathrm{~m}$ & $3.23 \mathrm{E}+09$ & $1.24 \mathrm{E}-04$ & \\
\hline Bk-247 & 3.39E-01 & $1.18 \mathrm{E}+06$ & Bk-247 & $3.39 \mathrm{E}-01$ & $1.18 \mathrm{E}+06$ & \\
\hline C-14 & $5.39 \mathrm{E}+09$ & $7.42 \mathrm{E}-05$ & C-14 & $5.43 \mathrm{E}+09$ & $7.36 \mathrm{E}-05$ & \\
\hline $\mathrm{Ca}-41$ & $1.09 \mathrm{E}+09$ & $3.67 \mathrm{E}-04$ & $\mathrm{Ca}-41$ & $1.10 \mathrm{E}+09$ & $3.65 \mathrm{E}-04$ & \\
\hline Cd-113 & $6.57 \mathrm{E}+09$ & $6.09 \mathrm{E}-05$ & Cd-113 & $6.57 \mathrm{E}+09$ & $6.09 \mathrm{E}-05$ & \\
\hline Cf-249 & $3.37 \mathrm{E}-01$ & $1.19 \mathrm{E}+06$ & Cf-249 & $3.38 \mathrm{E}-01$ & $1.18 \mathrm{E}+06$ & \\
\hline Cf-251 & $1.58 \mathrm{E}+06$ & $2.53 \mathrm{E}-01$ & Cf-251 & $1.58 \mathrm{E}+06$ & $2.53 \mathrm{E}-01$ & \\
\hline Cl-36 & $9.30 \mathrm{E}+09$ & $4.30 \mathrm{E}-05$ & $\mathrm{Cl}-36$ & $9.39 \mathrm{E}+09$ & $4.26 \mathrm{E}-05$ & \\
\hline $\mathrm{Cm}-245$ & $9.10 \mathrm{E}+05$ & $4.39 \mathrm{E}-01$ & $\mathrm{Cm}-245$ & $1.52 \mathrm{E}+06$ & $2.63 \mathrm{E}-01$ & $67.03 \%$ \\
\hline $\mathrm{Cm}-246$ & $1.36 \mathrm{E}+03$ & $2.94 \mathrm{E}+02$ & $\mathrm{Cm}-246$ & $1.36 \mathrm{E}+03$ & $2.94 \mathrm{E}+02$ & \\
\hline $\mathrm{Cm}-247$ & $2.88 \mathrm{E}+09$ & $1.39 \mathrm{E}-04$ & $\mathrm{Cm}-247$ & $3.16 \mathrm{E}+09$ & $1.26 \mathrm{E}-04$ & \\
\hline $\mathrm{Cm}-248$ & $9.44 \mathrm{E}+09$ & $4.24 \mathrm{E}-05$ & $\mathrm{Cm}-248$ & $9.44 \mathrm{E}+09$ & $4.24 \mathrm{E}-05$ & \\
\hline $\mathrm{Cm}-250$ & $2.87 \mathrm{E}+06$ & $1.39 \mathrm{E}-01$ & $\mathrm{Cm}-250$ & $2.87 \mathrm{E}+06$ & $1.39 \mathrm{E}-01$ & \\
\hline Cs-135 & $1.24 \mathrm{E}+08$ & $3.23 \mathrm{E}-03$ & Cs-135 & $1.24 \mathrm{E}+08$ & $3.23 \mathrm{E}-03$ & \\
\hline $\mathrm{Fe}-60$ & $3.56 \mathrm{E}+09$ & $1.12 \mathrm{E}-04$ & $\mathrm{Fe}-60$ & $4.22 \mathrm{E}+09$ & $9.47 \mathrm{E}-05$ & $18.54 \%$ \\
\hline \multirow[t]{2}{*}{ Gd-152 } & $2.34 \mathrm{E}+09$ & $1.71 \mathrm{E}-04$ & Gd-152 & $2.34 \mathrm{E}+09$ & $1.71 \mathrm{E}-04$ & \\
\hline & & & Ge-68 & $1.94 \mathrm{E}+07$ & $2.06 \mathrm{E}-02$ & \\
\hline H-3 & $1.24 \mathrm{E}+09$ & $3.22 \mathrm{E}-04$ & $\mathrm{H}-3$ & $1.39 \mathrm{E}+09$ & $2.87 \mathrm{E}-04$ & $12.10 \%$ \\
\hline Hf-182 & $6.20 \mathrm{E}+08$ & $6.46 \mathrm{E}-04$ & Hf-182 & $1.07 \mathrm{E}+09$ & $3.73 \mathrm{E}-04$ & $72.58 \%$ \\
\hline $\mathrm{Hg}-194$ & $1.66 \mathrm{E}+10$ & $2.41 \mathrm{E}-05$ & $\mathrm{Hg}-194$ & $1.67 \mathrm{E}+10$ & $2.39 \mathrm{E}-05$ & \\
\hline Ho-166m & $6.06 \mathrm{E}+06$ & $6.60 \mathrm{E}-02$ & Ho-166m & $6.06 \mathrm{E}+06$ & $6.60 \mathrm{E}-02$ & \\
\hline I-129 & $3.24 \mathrm{E}+12$ & $1.24 \mathrm{E}-07$ & I-129 & $3.31 \mathrm{E}+12$ & $1.21 \mathrm{E}-07$ & \\
\hline In-115 & $1.78 \mathrm{E}+09$ & $2.25 \mathrm{E}-04$ & In-115 & $1.78 \mathrm{E}+09$ & $2.25 \mathrm{E}-04$ & \\
\hline Ir-192m & $1.10 \mathrm{E}+05$ & $3.62 \mathrm{E}+00$ & Ir-192m & $1.11 \mathrm{E}+05$ & $3.62 \mathrm{E}+00$ & \\
\hline $\mathrm{K}-40$ & $7.04 \mathrm{E}+09$ & $5.68 \mathrm{E}-05$ & $\mathrm{~K}-40$ & $7.05 \mathrm{E}+09$ & $5.68 \mathrm{E}-05$ & \\
\hline La-137 & $1.58 \mathrm{E}+06$ & $2.53 \mathrm{E}-01$ & La-137 & $1.58 \mathrm{E}+06$ & $2.53 \mathrm{E}-01$ & \\
\hline La-138 & $2.72 \mathrm{E}+07$ & $1.47 \mathrm{E}-02$ & La-138 & $2.72 \mathrm{E}+07$ & $1.47 \mathrm{E}-02$ & \\
\hline Lu-176 & $5.09 \mathrm{E}+08$ & $7.86 \mathrm{E}-04$ & Lu-176 & $5.09 \mathrm{E}+08$ & $7.86 \mathrm{E}-04$ & \\
\hline Mn-53 & $1.34 \mathrm{E}+07$ & $2.99 \mathrm{E}-02$ & $\mathrm{Mn}-53$ & $1.34 \mathrm{E}+07$ & $2.99 \mathrm{E}-02$ & \\
\hline Mo-93 & $4.69 \mathrm{E}+08$ & $8.54 \mathrm{E}-04$ & Mo-93 & $8.34 \mathrm{E}+08$ & $4.80 \mathrm{E}-04$ & $77.83 \%$ \\
\hline Nb-94 & $2.52 \mathrm{E}+08$ & $1.59 \mathrm{E}-03$ & Nb-94 & $2.52 \mathrm{E}+08$ & $1.59 \mathrm{E}-03$ & \\
\hline Ni-59 & $3.16 \mathrm{E}+06$ & $1.26 \mathrm{E}-01$ & Ni-59 & $3.16 \mathrm{E}+06$ & $1.26 \mathrm{E}-01$ & \\
\hline Np-236a & $9.56 \mathrm{E}+11$ & $4.18 \mathrm{E}-07$ & $\mathrm{~Np}-236 \mathrm{a}$ & $1.12 \mathrm{E}+12$ & $3.56 \mathrm{E}-07$ & $17.15 \%$ \\
\hline Np-237 & $2.61 \mathrm{E}+12$ & $1.53 \mathrm{E}-07$ & Np-237 & $2.62 \mathrm{E}+12$ & $1.52 \mathrm{E}-07$ & \\
\hline $\mathrm{Pa}-231$ & $4.12 \mathrm{E}+10$ & $9.72 \mathrm{E}-06$ & Pa-231 & $4.78 \mathrm{E}+11$ & $8.36 \mathrm{E}-07$ & $1060.19 \%$ \\
\hline $\mathrm{Pb}-202$ & $6.87 \mathrm{E}+08$ & $5.82 \mathrm{E}-04$ & $\mathrm{~Pb}-202$ & $7.17 \mathrm{E}+08$ & $5.58 \mathrm{E}-04$ & \\
\hline $\mathrm{Pb}-205$ & $2.72 \mathrm{E}+07$ & $1.47 \mathrm{E}-02$ & $\mathrm{~Pb}-205$ & $2.72 \mathrm{E}+07$ & $1.47 \mathrm{E}-02$ & \\
\hline Pd-107 & $2.25 \mathrm{E}+07$ & $1.78 \mathrm{E}-02$ & Pd-107 & $2.25 \mathrm{E}+07$ & $1.78 \mathrm{E}-02$ & \\
\hline Pt-193 & $8.47 \mathrm{E}-02$ & $4.72 \mathrm{E}+06$ & Pt-193 & $8.53 \mathrm{E}-02$ & $4.69 \mathrm{E}+06$ & \\
\hline
\end{tabular}

Table 3-3 Comparison of Previous Analyses with Automated Screening 
WSRC-TR-2005-00203, REVISION 0

\begin{tabular}{|c|c|c|c|c|c|c|}
\hline \multicolumn{3}{|c|}{ Ref. 2} & \multicolumn{3}{|c|}{ Automated GW } & \multirow[b]{2}{*}{$\begin{array}{l}\text { \% } \\
\text { difference }\end{array}$} \\
\hline Radionuclide & $\begin{array}{c}\text { mrem per } \\
1.00 \mathrm{E}+07 \\
\mathrm{Ci}\end{array}$ & $\begin{array}{c}\text { Trigger } \\
\text { Value Ci } \\
\text { to give } \\
0.04 \\
\text { mrem }\end{array}$ & Radionuclide & $\begin{array}{c}\text { mrem per } \\
1.00 \mathrm{E}+07 \\
\mathrm{Ci}\end{array}$ & $\begin{array}{c}\text { Trigger } \\
\text { Value Ci } \\
\text { to give } \\
0.04 \\
\text { mrem }\end{array}$ & \\
\hline Pu-239 & $3.22 \mathrm{E}+10$ & $1.24 \mathrm{E}-05$ & $\mathrm{Pu}-239$ & $3.22 \mathrm{E}+10$ & $1.24 \mathrm{E}-05$ & \\
\hline $\mathrm{Pu}-240$ & $1.80 \mathrm{E}+10$ & $2.22 \mathrm{E}-05$ & $\mathrm{Pu}-240$ & $1.80 \mathrm{E}+10$ & $2.22 \mathrm{E}-05$ & \\
\hline $\mathrm{Pu}-242$ & $3.74 \mathrm{E}+10$ & $1.07 \mathrm{E}-05$ & $\mathrm{Pu}-242$ & $3.74 \mathrm{E}+10$ & $1.07 \mathrm{E}-05$ & \\
\hline $\mathrm{Pu}-244$ & $3.77 \mathrm{E}+12$ & $1.06 \mathrm{E}-07$ & $\mathrm{Pu}-244$ & $3.77 \mathrm{E}+12$ & $1.06 \mathrm{E}-07$ & \\
\hline Ra-226 & $4.26 \mathrm{E}+07$ & 9.39E-03 & Ra-226 & $2.19 \mathrm{E}+08$ & $1.82 \mathrm{E}-03$ & $414.08 \%$ \\
\hline $\mathrm{Rb}-87$ & $4.99 \mathrm{E}+08$ & $8.02 \mathrm{E}-04$ & $\mathrm{Rb}-87$ & $4.99 \mathrm{E}+08$ & $8.02 \mathrm{E}-04$ & \\
\hline Re-186m & $3.84 \mathrm{E}+09$ & $1.04 \mathrm{E}-04$ & Re-186m & $6.54 \mathrm{E}+09$ & $6.11 \mathrm{E}-05$ & $70.31 \%$ \\
\hline Re-187 & $9.02 \mathrm{E}+06$ & $4.43 \mathrm{E}-02$ & Re-187 & $9.04 \mathrm{E}+06$ & $4.43 \mathrm{E}-02$ & \\
\hline Se-79 & $2.12 \mathrm{E}+08$ & $1.89 \mathrm{E}-03$ & Se-79 & $2.12 \mathrm{E}+08$ & $1.89 \mathrm{E}-03$ & \\
\hline Si-32 & $1.34 \mathrm{E}+08$ & 2.99E-03 & Si-32 & $5.25 \mathrm{E}+08$ & 7.62E-04 & $291.79 \%$ \\
\hline Sm-146 & $3.01 \mathrm{E}+09$ & $1.33 \mathrm{E}-04$ & Sm-146 & $3.01 \mathrm{E}+09$ & $1.33 \mathrm{E}-04$ & \\
\hline Sm-147 & $2.74 \mathrm{E}+09$ & $1.46 \mathrm{E}-04$ & Sm-147 & $2.74 \mathrm{E}+09$ & $1.46 \mathrm{E}-04$ & \\
\hline Sn-126 & $1.05 \mathrm{E}+09$ & $3.81 \mathrm{E}-04$ & Sn-126 & $1.13 \mathrm{E}+09$ & $3.55 \mathrm{E}-04$ & \\
\hline Sr-90 & $1.48 \mathrm{E}+08$ & $2.70 \mathrm{E}-03$ & Sr-90 & $1.61 \mathrm{E}+08$ & $2.48 \mathrm{E}-03$ & \\
\hline Ta-180 & $1.14 \mathrm{E}+08$ & $3.50 \mathrm{E}-03$ & Ta-180 & $1.14 \mathrm{E}+08$ & $3.50 \mathrm{E}-03$ & \\
\hline Tc-97 & $2.68 \mathrm{E}+09$ & 1.49E-04 & Tc-97 & $2.77 \mathrm{E}+09$ & $1.44 \mathrm{E}-04$ & \\
\hline Tc-98 & $6.76 \mathrm{E}+10$ & 5.92E-06 & Tc-98 & $6.97 \mathrm{E}+10$ & 5.74E-06 & \\
\hline Tc-99 & $2.45 \mathrm{E}+10$ & $1.63 \mathrm{E}-05$ & Tc-99 & $2.53 \mathrm{E}+10$ & $1.58 \mathrm{E}-05$ & \\
\hline Te-123 & $9.80 \mathrm{E}+07$ & $4.08 \mathrm{E}-03$ & Te-123 & $9.80 \mathrm{E}+07$ & $4.08 \mathrm{E}-03$ & \\
\hline Th-229 & $1.68 \mathrm{E}+06$ & $2.39 \mathrm{E}-01$ & Th-229 & $2.06 \mathrm{E}+06$ & $1.95 \mathrm{E}-01$ & $22.62 \%$ \\
\hline Th-230 & $2.52 \mathrm{E}+08$ & $1.59 \mathrm{E}-03$ & Th-230 & $1.63 \mathrm{E}+09$ & $2.45 \mathrm{E}-04$ & $546.83 \%$ \\
\hline Th-232 & $2.46 \mathrm{E}+09$ & $1.63 \mathrm{E}-04$ & Th-232 & $5.29 \mathrm{E}+09$ & $7.56 \mathrm{E}-05$ & $115.04 \%$ \\
\hline Ti-44 & $6.66 \mathrm{E}+11$ & $6.01 \mathrm{E}-07$ & Ti-44 & $7.43 \mathrm{E}+11$ & $5.38 \mathrm{E}-07$ & $11.56 \%$ \\
\hline U-233 & $7.04 \mathrm{E}+08$ & $5.68 \mathrm{E}-04$ & U-233 & $2.00 \mathrm{E}+09$ & $2.00 \mathrm{E}-04$ & $184.09 \%$ \\
\hline U-234 & $7.11 \mathrm{E}+08$ & $5.63 \mathrm{E}-04$ & U-234 & $7.76 \mathrm{E}+08$ & $5.15 \mathrm{E}-04$ & \\
\hline U-235 & $7.28 \mathrm{E}+08$ & 5.49E-04 & U-235 & $9.74 \mathrm{E}+09$ & $4.11 \mathrm{E}-05$ & $1237.91 \%$ \\
\hline U-236 & $7.12 \mathrm{E}+08$ & $5.62 \mathrm{E}-04$ & U-236 & $7.12 \mathrm{E}+08$ & $5.62 \mathrm{E}-04$ & \\
\hline U-238 & $6.88 \mathrm{E}+08$ & 5.81E-04 & U-238 & $8.32 \mathrm{E}+08$ & $4.81 \mathrm{E}-04$ & $20.93 \%$ \\
\hline V-49 & $3.49 \mathrm{E}+07$ & $1.15 \mathrm{E}-02$ & V-49 & $5.39 \mathrm{E}+07$ & 7.42E-03 & $54.44 \%$ \\
\hline Zr-93 & $1.07 \mathrm{E}+07$ & $3.74 \mathrm{E}-02$ & Zr-93 & $1.75 \mathrm{E}+07$ & $2.29 \mathrm{E}-02$ & $63.55 \%$ \\
\hline
\end{tabular}

Table 3-3 Comparison of Previous Analysis with Automated Screening (continued)

\subsubsection{Comparison with NCRP}

It is difficult to make a direct comparison with the NCRP screening factors because while most of the data used in its calculation can be divined there are still some data which are not known. The NCRP lists the maximum value of the screening factor calculated for any time interval but does not say which interval was used. It does not state what soil density was used nor does it give a reference for decay fractions. In addition, SRS derived leach rates are used for most radionuclides of interest in the automated analysis. In order to make any sort of comparison a radionuclide was found which did not have a decay chain, used the same half life, and had the same leach rate as was used in the NCRP. The radionuclide arbitrarily chosen was Co-60. 
While trying to reconcile the two calculations another idiosyncrasy of the NCRP tables was discovered. Buried in Section 4.2 of Ref. R. 6-2 is a statement that during the period of administrative control the waste layer is covered by an additional 1 meter of earth. Since it is unknown what time delay was selected it is possible that there are two time delays, 2 and 10 years, which have a total depth of 1.5 meters versus only the waste depth of 0.5 meters. This appears to be the case for Co-60.

A manual calculation run to compare with the NCRP value, using only the waste depth, had a value of $1.79 \mathrm{E}-13$ (using the specified minimum delay of 2 years) versus the automated groundwater generated value of 1.91E-13. However, neither of these values agreed with the NCRP's 5.8e-14. Using a total waste depth of 1.5 meters, assuming the maximum dose occurred during the period of administrative control, the manual calculation yielded 5.96E14. With the open questions about some of the values used for the generation of the NCRP's values, this shows good agreement.

\subsubsection{Daughters with their leach rates}

This section discusses the results obtained using Equation 6. As previously discussed, this form of the screening factor equation is used because of the limitations placed on the calculation by using only the parent leach rate. A low parent leach rate will cause the parent to meet the screening criterion even though daughters may exceed that criterion. The philosophy behind using this equation is the desire to find which parents in NCRP Table 3-1 lead to exceeding the screening limit. Rather than having triggers for all the radionuclides in the table, by using this equation one can compute the actual screening value and hopefully eliminate some of those radionuclides from subsequent analyses.

The results presented in Table 3-4 are those from the comparison with Ref. R. 6-3. The radionuclides are those listed in NCRP Table 3-1. If a value in the "Dose" column exceeds the screening criterion of 0.04 and is not included in the list of radionuclides already screened out by Equation 4 then it is highlighted in red. The table shows that 13 additional radionuclides failed the screen. This is a small fraction of the entire list. If this methodology were adopted it would reduce the number of radionuclides which need to be analyzed or have trigger values. (The blanks in the table are those radionuclides which (using Equation 4) had a screening factor calculated in double precision as zero.) 
WSRC-TR-2005-00203, REVISION 0

\begin{tabular}{|c|c|c|c|}
\hline Nuc & Dose* & Nuc & Dose* \\
\hline Am-237 & 1.6976E+02 & Pu-236 & $2.7040 \mathrm{E}-76$ \\
\hline Am-241 & $4.2235 E+08$ & Pu-237 & $1.5207 \mathrm{E}+05$ \\
\hline Am-243 & $9.3988 E+08$ & Pu-238 & $2.5504 \mathrm{E}+05$ \\
\hline Ba-131 & & Pu-239 & $3.2186 \mathrm{E}+10$ \\
\hline Ba-140 & & Pu-240 & $1.8028 \mathrm{E}+10$ \\
\hline $\mathrm{Bi}-210$ & & Pu-241 & $1.3950 \mathrm{E}+07$ \\
\hline Bk-249 & $1.9155 E+04$ & $\mathrm{Pu}-242$ & $3.7370 \mathrm{E}+10$ \\
\hline Ce-143 & & Ra-225 & \\
\hline Cf-249 & $7.6621 E+06$ & Ra-226 & $4.2611 \mathrm{E}+07$ \\
\hline Cf-252 & $7.0740 \mathrm{E}+04$ & Ra-228 & \\
\hline Cm-241 & 8.7971E+04 & Ru-97 & $8.4314 \mathrm{E}+00$ \\
\hline $\mathrm{Cm}-242$ & 1.2955E+03 & Sb-125 & 6.9138E-115 \\
\hline $\mathrm{Cm}-244$ & 4.8514E+07 & Se-73 & \\
\hline $\mathrm{Cm}-245$ & $4.0050 \mathrm{E}+08$ & Si-32 & $1.3412 \mathrm{E}+08$ \\
\hline $\mathrm{Cm}-248$ & $9.4458 E+09$ & Sn-121m & $1.5065 \mathrm{E}-10$ \\
\hline Es-253 & $1.2197 \mathrm{E}+03$ & Sn-127 & \\
\hline Ge-68 & 3.8432E-12 & Sr-85m & \\
\hline $\mathrm{Hf}-172$ & & Sr-91 & \\
\hline $\mathrm{I}-123$ & 1.4759E-07 & Th-228 & \\
\hline Ir-192m & $1.1060 \mathrm{E}+05$ & Th-232 & $2.4607 \mathrm{E}+09$ \\
\hline La-141 & & $\mathrm{U}-230$ & 9.9209E-84 \\
\hline $\mathrm{Nb}-95 \mathrm{~m}$ & & $\mathrm{U}-232$ & 7.9973E-75 \\
\hline $\mathrm{Nd}-147$ & $7.7824 \mathrm{E}-04$ & U-233 & $7.0375 \mathrm{E}+08$ \\
\hline $\mathrm{Ni}-57$ & & U-234 & $7.1093 \mathrm{E}+08$ \\
\hline $\mathrm{Pa}-230$ & $1.6343 \mathrm{E}+02$ & $\mathrm{U}-235$ & $1.5900 \mathrm{E}+09$ \\
\hline $\mathrm{Pa}-231$ & $4.1171 E+10$ & $\mathrm{U}-238$ & $6.9010 \mathrm{E}+08$ \\
\hline \multirow[t]{4}{*}{$\mathrm{Pb}-210$} & 4.1235E-81 & W-188 & \\
\hline & & $\mathrm{Y}-91 \mathrm{~m}$ & \\
\hline & & Zr-93 & $1.0701 \mathrm{E}+07$ \\
\hline & & Zr-95 & \\
\hline
\end{tabular}

Table 3-4 Daughters with their leach rates

Table 3-5 shows the comparison of the doses $\left(\mathrm{mrem} / 10^{7} \mathrm{Ci}\right.$ ) of the radionuclides which failed the screening criterion for the three calculational methods. While this list at first may appear to be longer than the list in Table 3-3 it is in fact shorter. Table 3-3 does not show the radionuclides from NCRP Table 3-1 for which the previous methodology calculated trigger values. The previous methodology would have had a total list length of approximately 130 radionuclides which needed to be accounted for while the list shown in Table 3-5 is only 86 long. 
WSRC-TR-2005-00203, REVISION 0

\begin{tabular}{|c|c|c|c|c|c|c|c|}
\hline Nuclide & Equation 3 & Equation 4 & Equation 6 & Nuclide & Equation 3 & Equation 4 & Equation 6 \\
\hline $\mathrm{Ag}-108 \mathrm{~m}$ & $2.9028 \mathrm{E}+03$ & $2.9111 \mathrm{E}+03$ & $2.9111 \mathrm{E}+03$ & $\mathrm{Ni}-59$ & $3.1648 \mathrm{E}+06$ & $3.1649 \mathrm{E}+06$ & $3.1649 \mathrm{E}+06$ \\
\hline $\mathrm{Al}-26$ & $4.5653 \mathrm{E}+11$ & $4.9832 \mathrm{E}+11$ & $4.9832 E+11$ & $\mathrm{~Np}-236 \mathrm{a}$ & $9.5633 \mathrm{E}+11$ & $1.1237 \mathrm{E}+12$ & $9.5960 \mathrm{E}+11$ \\
\hline Am-237 & $0.0000 E+00$ & $0.0000 \mathrm{E}+00$ & $1.6976 \mathrm{E}+02$ & $\mathrm{~Np}-237$ & $2.6094 \mathrm{E}+12$ & $2.6239 \mathrm{E}+12$ & $2.6183 E+12$ \\
\hline Am-241 & 5.3115E-24 & 5.3158E-24 & $4.2235 E+08$ & $\mathrm{~Pa}-230$ & $0.0000 \mathrm{E}+00$ & $0.0000 \mathrm{E}+00$ & $1.6343 \mathrm{E}+02$ \\
\hline Am-243 & $7.4531 \mathrm{E}+07$ & $7.4672 \mathrm{E}+07$ & $9.3988 E+08$ & $\mathrm{~Pa}-231$ & $4.1169 \mathrm{E}+10$ & $4.7830 \mathrm{E}+11$ & $4.1171 E+10$ \\
\hline $\mathrm{Be}-10$ & $1.5152 \mathrm{E}+08$ & $1.5153 \mathrm{E}+08$ & $1.5153 E+08$ & $\mathrm{~Pb}-202$ & $6.8735 \mathrm{E}+08$ & $7.1663 E+08$ & $6.8740 \mathrm{E}+08$ \\
\hline $\mathrm{Bi}-210 \mathrm{~m}$ & $3.2286 \mathrm{E}+09$ & $3.2291 \mathrm{E}+09$ & $3.2291 E+09$ & $\mathrm{~Pb}-205$ & $2.7160 \mathrm{E}+07$ & $2.7161 \mathrm{E}+07$ & $2.7161 \mathrm{E}+07$ \\
\hline Bk-247 & 3.3907E-01 & 3.3916E-01 & $4.0770 \mathrm{E}+07$ & $\mathrm{Pd}-107$ & $2.2491 \mathrm{E}+07$ & $2.2498 \mathrm{E}+07$ & $2.2498 \mathrm{E}+07$ \\
\hline Bk-249 & $0.0000 \mathrm{E}+00$ & $0.0000 \mathrm{E}+00$ & $1.9155 \mathrm{E}+04$ & Pt-193 & 8.4713E-02 & 8.5329E-02 & 8.5329E-02 \\
\hline $\mathrm{C}-14$ & $5.3908 \mathrm{E}+09$ & $5.4348 \mathrm{E}+09$ & $5.4348 \mathrm{E}+09$ & $\mathrm{Pu}-237$ & $0.0000 \mathrm{E}+00$ & $0.0000 \mathrm{E}+00$ & $1.5207 E+05$ \\
\hline Ca-41 & $1.0913 \mathrm{E}+09$ & $1.0951 E+09$ & $1.0951 E+09$ & Pu-238 & $6.4778 \mathrm{E}-16$ & $6.5038 \mathrm{E}-16$ & $2.5504 \mathrm{E}+05$ \\
\hline $\mathrm{Cd}-113$ & $6.5712 \mathrm{E}+09$ & $6.5727 \mathrm{E}+09$ & $6.5727 E+09$ & Pu-239 & $3.2183 \mathrm{E}+10$ & $3.2186 \mathrm{E}+10$ & $3.2186 \mathrm{E}+10$ \\
\hline Cf-249 & 3.3747E-01 & 3.3781E-01 & $7.6621 E+06$ & $\mathrm{Pu}-240$ & $1.8026 \mathrm{E}+10$ & $1.8028 \mathrm{E}+10$ & $1.8028 \mathrm{E}+10$ \\
\hline Cf-251 & $1.5821 \mathrm{E}+06$ & $1.5827 \mathrm{E}+06$ & $1.5827 \mathrm{E}+06$ & Pu-241 & 9.5450E-149 & 1.5464E-148 & $1.3950 \mathrm{E}+07$ \\
\hline Cf-252 & $0.0000 \mathrm{E}+00$ & $0.0000 \mathrm{E}+00$ & $7.0740 \mathrm{E}+04$ & $\mathrm{Pu}-242$ & $3.7368 \mathrm{E}+10$ & $3.7370 \mathrm{E}+10$ & $3.7370 \mathrm{E}+10$ \\
\hline $\mathrm{Cl}-36$ & $9.3018 \mathrm{E}+09$ & $9.3891 E+09$ & $9.3891 E+09$ & $\mathrm{Pu}-244$ & 3.7673E+12 & $3.7716 \mathrm{E}+12$ & $3.7693 E+12$ \\
\hline $\mathrm{Cm}-241$ & $0.0000 E+00$ & $0.0000 E+00$ & $8.7971 E+04$ & $\mathrm{Ra}-226$ & $4.2600 \mathrm{E}+07$ & $2.1930 \mathrm{E}+08$ & $4.2611 E+07$ \\
\hline $\mathrm{Cm}-242$ & $0.0000 \mathrm{E}+00$ & $0.0000 \mathrm{E}+00$ & $1.2955 \mathrm{E}+03$ & $\mathrm{Rb}-87$ & 4.9857E+08 & $4.9874 \mathrm{E}+08$ & $4.9874 \mathrm{E}+08$ \\
\hline $\mathrm{Cm}-244$ & $0.0000 E+00$ & $0.0000 \mathrm{E}+00$ & $4.8514 \mathrm{E}+07$ & $\mathrm{Re}-186 \mathrm{~m}$ & $3.8397 \mathrm{E}+09$ & $6.5430 \mathrm{E}+09$ & $3.8464 \mathrm{E}+09$ \\
\hline $\mathrm{Cm}-245$ & $9.1033 E+05$ & $1.5230 \mathrm{E}+06$ & $4.0050 \mathrm{E}+08$ & Re-187 & $9.0229 \mathrm{E}+06$ & $9.0386 \mathrm{E}+06$ & $9.0386 \mathrm{E}+06$ \\
\hline $\mathrm{Cm}-246$ & $1.3595 \mathrm{E}+03$ & $1.3596 \mathrm{E}+03$ & $6.4005 \mathrm{E}+07$ & Ru-97 & $0.0000 \mathrm{E}+00$ & $0.0000 \mathrm{E}+00$ & $8.4314 \mathrm{E}+00$ \\
\hline $\mathrm{Cm}-247$ & $2.8841 \mathrm{E}+09$ & $3.1626 \mathrm{E}+09$ & $2.9324 \mathrm{E}+09$ & Se-79 & $2.1156 \mathrm{E}+08$ & $2.1159 \mathrm{E}+08$ & $2.1159 \mathrm{E}+08$ \\
\hline $\mathrm{Cm}-248$ & $9.4361 E+09$ & $9.4361 E+09$ & $9.4458 \mathrm{E}+09$ & Si-32 & $1.3395 \mathrm{E}+08$ & $5.2488 \mathrm{E}+08$ & $1.3412 \mathrm{E}+08$ \\
\hline $\mathrm{Cm}-250$ & $2.8679 \mathrm{E}+06$ & $2.8698 \mathrm{E}+06$ & $4.3825 E+06$ & Sm-146 & $3.0111 \mathrm{E}+09$ & $3.0113 \mathrm{E}+09$ & $3.0113 E+09$ \\
\hline Cs-135 & $1.2378 \mathrm{E}+08$ & $1.2378 \mathrm{E}+08$ & $1.2378 \mathrm{E}+08$ & Sm-147 & $2.7414 \mathrm{E}+09$ & $2.7416 \mathrm{E}+09$ & $2.7416 \mathrm{E}+09$ \\
\hline Es-253 & $0.0000 E+00$ & $0.0000 E+00$ & 1.2197E+03 & Sn-126 & $1.0495 E+09$ & 1.1277E+09 & $1.0497 \mathrm{E}+09$ \\
\hline Fe-60 & $3.5633 E+09$ & $4.2223 E+09$ & $3.5636 \mathrm{E}+09$ & Sr-90 & $1.4791 \mathrm{E}+08$ & $1.6109 \mathrm{E}+08$ & $1.4993 \mathrm{E}+08$ \\
\hline Gd-152 & $2.3365 E+09$ & $2.3367 \mathrm{E}+09$ & $2.3367 E+09$ & Ta-180 & $1.1435 E+08$ & $1.1436 \mathrm{E}+08$ & $1.1436 \mathrm{E}+08$ \\
\hline Ge-68 & 2.3726E-12 & $1.9445 \mathrm{E}+07$ & 3.8432E-12 & Tc-97 & $2.6844 \mathrm{E}+09$ & $2.7705 \mathrm{E}+09$ & $2.7705 E+09$ \\
\hline $\mathrm{H}-3$ & $1.2433 \mathrm{E}+09$ & $1.3943 \mathrm{E}+09$ & $1.3943 E+09$ & Tc-98 & $6.7572 \mathrm{E}+10$ & $6.9740 \mathrm{E}+10$ & $6.9740 \mathrm{E}+10$ \\
\hline $\mathrm{Hf}-182$ & $6.1956 \mathrm{E}+08$ & $1.0711 \mathrm{E}+09$ & $6.1967 E+08$ & Tc-99 & $2.4517 \mathrm{E}+10$ & $2.5303 E+10$ & $2.5303 E+10$ \\
\hline $\mathrm{Hg}-194$ & $1.6626 \mathrm{E}+10$ & $1.6725 \mathrm{E}+10$ & $1.6663 \mathrm{E}+10$ & Te-123 & $9.7999 \mathrm{E}+07$ & $9.8013 \mathrm{E}+07$ & $9.8013 \mathrm{E}+07$ \\
\hline Ho-166m & $6.0608 \mathrm{E}+06$ & $6.0630 \mathrm{E}+06$ & $6.0630 \mathrm{E}+06$ & Th-229 & $1.6752 \mathrm{E}+06$ & $2.0562 E+06$ & $1.6753 \mathrm{E}+06$ \\
\hline $\mathrm{I}-129$ & $3.2355 \mathrm{E}+12$ & $3.3079 \mathrm{E}+12$ & $3.3079 \mathrm{E}+12$ & Th-230 & $2.5151 \mathrm{E}+08$ & $1.6309 \mathrm{E}+09$ & $2.6417 E+08$ \\
\hline In-115 & $1.7774 \mathrm{E}+09$ & $1.7775 \mathrm{E}+09$ & $1.7775 \mathrm{E}+09$ & Th-232 & $2.4607 \mathrm{E}+09$ & $5.2924 \mathrm{E}+09$ & $2.4607 E+09$ \\
\hline Ir-192m & $1.1042 \mathrm{E}+05$ & $1.1060 \mathrm{E}+05$ & $1.1060 \mathrm{E}+05$ & Ti-44 & $6.6575 E+11$ & $7.4346 \mathrm{E}+11$ & $7.3185 E+11$ \\
\hline $\mathrm{K}-40$ & $7.0400 \mathrm{E}+09$ & $7.0482 \mathrm{E}+09$ & $7.0482 \mathrm{E}+09$ & U-233 & $7.0373 E+08$ & $1.9952 E+09$ & $7.0375 \mathrm{E}+08$ \\
\hline La-137 & $1.5841 \mathrm{E}+06$ & $1.5842 \mathrm{E}+06$ & $1.5842 \mathrm{E}+06$ & U-234 & $7.1061 \mathrm{E}+08$ & $7.7648 \mathrm{E}+08$ & $7.1093 \mathrm{E}+08$ \\
\hline La-138 & $2.7205 E+07$ & $2.7206 \mathrm{E}+07$ & $2.7206 \mathrm{E}+07$ & $\mathrm{U}-235$ & $7.2806 \mathrm{E}+08$ & $9.7400 \mathrm{E}+09$ & $1.5900 \mathrm{E}+09$ \\
\hline Lu-176 & $5.0895 E+08$ & $5.0904 E+08$ & $5.0904 \mathrm{E}+08$ & $\mathrm{U}-236$ & $7.1165 \mathrm{E}+08$ & $7.1166 \mathrm{E}+08$ & $7.1166 \mathrm{E}+08$ \\
\hline $\mathrm{Mn}-53$ & $1.3384 \mathrm{E}+07$ & $1.3388 \mathrm{E}+07$ & $1.3388 \mathrm{E}+07$ & $\mathrm{U}-238$ & $6.8807 \mathrm{E}+08$ & $8.3166 \mathrm{E}+08$ & $6.9010 \mathrm{E}+08$ \\
\hline Mo-93 & $4.6860 \mathrm{E}+08$ & $8.3381 E+08$ & $4.6946 \mathrm{E}+08$ & $V-49$ & $3.4860 \mathrm{E}+07$ & $5.3886 \mathrm{E}+07$ & $5.3886 \mathrm{E}+07$ \\
\hline $\mathrm{Nb}-94$ & $2.5210 \mathrm{E}+08$ & $2.5213 E+08$ & $2.5213 E+08$ & Zr-93 & $1.0700 \mathrm{E}+07$ & $1.7479 \mathrm{E}+07$ & $1.0701 E+07$ \\
\hline
\end{tabular}




\section{Table 3-5 Comparison of dose $\left(\mathrm{mrem} / \mathbf{1 0}^{7} \mathrm{Ci}\right)$ for three calculational methods}

The above table shows the effects of adding to the rigor of the calculation. The values in the Equation 4 column are always larger than the values in the Equation 3 column. This is because of the addition of the daughter decay fractions times the dose factors. The Equation 6 column shows the effect of using the daughter leach factors. Because of the interaction of the transport and radioactive decay of all the daughters in a decay chain, it is impossible to tell whether an Equation 6 column value will be either greater or less than its corresponding Equation 4 column value. The Equation 6 column gives the most realistic (and rigorous) calculation of the screening factors and as such should be the method used.

\subsection{CONCLUSIONS}

This Automated Groundwater Screening analysis duplicates previous analyses and provides a means to rigorously apply the NCRP methodology. The method presented for treating significant daughters gives a means by which additional radionuclides may be screened out. Using the same problem definitions as Ref. R. 6-3 the automated groundwater screening found one additional nuclide, Ge-68, which failed the screening. It also found that 13 of the 57 radionuclides contained in NCRP Table 3.1 failed the screening. This reduces by 44 the number of radionuclides which need trigger values.

\subsection{FUTURE WORK}

There are areas where future work would enhance the Automated Groundwater Screening and both are tied to the time of the simulations.

\section{1 “TRANSIENT” CALCULATION}

A pseudo-transient calculation would allow the maximum SFGWs to be captured. The application already contains a time loop, but that time loop runs for seven discrete times (see Section 3.3.1.2). The loop could be modified to run a continuous (in a relative time scale) calculation easily. It could then be modified to keep track of the maximum SFGW for the radionuclides from the starting time to the ending time.

\subsection{INFILTRATION RATE}

The infiltration rate will change versus time, but the screening analysis selects only one value. The infiltration rate is very important, because a low infiltration rate will enhance the amount of decay that occurs before a radionuclide reaches a potential receptor and shortlived radionuclides can inadvertently be screened out.

There are at least four general candidates for selecting the most appropriate infiltration rate: 
1. the optimal infiltration rate for a fully functioning cap

2. the maximum infiltration rate prior to placement of a cap

3 . the average infiltration rate over the time range of analysis

4. the average infiltration rate to the time when the peak dose occurs for each radionuclide family

For highly mobile contaminants, the most appropriate choice appears to be the maximum infiltration rate. For other contaminants, the most appropriate initial choice appears to be the average infiltration rate over the time range of analysis, with consideration of choice 4 after the peak time is determined.

\subsection{HALF LIFE CONSISTENCY}

As shown in Table 3-1, there is some variation in the half life data sets. This can be extrapolated to the decay chains, branching fractions, dosage factors, etc. An approved set of these data should be created and made available to those doing analyses so that there is a consistency of basic data used by the various analysts at SRNL.

\subsection{LEACH RATES}

The Automated Groundwater Screening Analysis determines the effect of considering the leach rate of the daughter, rather than using the leach rate of the parent for all radionuclides in the decay chain. This change indicates that the screening factor may increase or decrease, depending on the decay chain of the radionuclide considered. However, the results are not conservative if the daughter leaches at a slower rate than does the parent, because the travel time depends both on how fast the parent moves before producing a daughter and how fast the daughter moves after being produced. A conservative approach would be to apply whichever leach rate is faster to the daughter (the parent only uses its own leach rate).

For each radionuclide, applying the fastest leach rate from among the precursors and the radionuclide of interest may produce overly conservative results. Future work should investigate this level of conservatism and determine the best approach to produce reasonably conservative results when applying leach rates for each radionuclide of the decay chain. 


\subsection{REFERENCES}

R. 6-1 Koffman, L. D., An Automated Inadvertent Intruder Analysis Application, WSRC-TR2004-00293, Savannah River Site, Aiken, SC 29898 (2004).

R. 6-2 Screening Models for Releases of Radionuclides to Atmosphere, Surface Water, and Ground. NCRP Report No. 123 Vol. I-II. National Council on Radiation Protection and Measurements, Bethesda, MD (1996).

R. 6-3 Cook, James R. and Wilhite, Elmer L. Special Analysis: Radionuclide Screening Analysis for E Area. WSRC-TR-2004-00294, Savannah River Site, Aiken, SC 29808 (2004)

R. 6-4 Eckerman, K. F. Extended Precision Chain Code Ver. 1.1. Oak Ridge National Laboratory, Oakridge, TN 37831-6383 (1996)

R. 6-5 Tuli, Jagdish K. Nuclear Wallet Cards. National Nuclear Data Center, Brookhaven National Laboratory, Upton, NY 11973-5000 
WSRC-TR-2005-00203, REVISION 0

\section{Appendix A. Design Check Instructions for Automated Groundwater Screening}

Following are the design check instructions. Cook's design check comments are included in italics. Koffman's design check follows.

Requirements for performing reviews of technical reports are defined in Procedure Manual E-7, 2.40, "Design Verification and Checking", and the complementary manual WSRC-IM2002-00011 Rev. 1 "Technical Report Design Check Guidelines" provides additional guidance. General lines of inquiry are defined in Table 1 of the latter. The purpose of these instructions is to define specific lines of inquiry appropriate for the concrete leaching model. The specific instructions given below are intended to supplement the general lines of inquiry, rather than constrain the scope of design checking.

1. Verify that Equation 3 is an accurate representation of the Screening Factor calculation in R. 6-2. (Cook)

Equation 3 accurately represents Equation 8.21 in $R$. 6-1when considering only [parent radionuclides

2. Verify that the results of Table 3-2 accurately compares the results of this analysis with the results of R. 6-3. This should show that the Automated analysis produces the same results as the reference if no daughters are used.(Cook)

Both the printed table in $R$. 6-.2and the spreadsheet on the CD Appendix to $R$. 6-1 present results to 2 significant digits (the printed table appears to have 3significant digits, but the third is always 0). The "Previous Report" column should be adjusted to match what is actually in Table 2 of R. 6-2.

3. Verify that Equation 4 and Equation 5 accurately reflect Equations 8.20 and 8.21 of R. 6-2. (Cook)

Equation 8.19 in R. 6-1 uses the notation $h$ as an index in the summation part of the equation. The report has used a mixture on $h$ and $n$ in Equation 5.

Equation 8.21 in $R$. 6-1 uses $N$ as the upper index for the summation. Equation 4 in the report uses $n$.

4. Assess Table 3-3 for reasonableness. The table compares previous results with the automated results with daughters. (Cook)

The results presented in Table 3-3 appears reasonable given the differences shown in the first paragraph of Section 3.3.1.2.

5. Assess the methodology proposed in Section 3.3.3. This section is the application of Equation 6. (Cook) 
The proposed methodology seems mathematically sound and should provide the basis for eliminating more radionuclides from the list of those to be considered.

6. Verify that the Automated Groundwater Screening coding has not adversely affected the Automated Intruder Analysis. (Koffman)

7. Verify that the equations of the report are correctly implemented in the coding (Koffman)

8. Verify that the $k_{d} s$, half lives, and dose factors are input correctly. The $k_{d} s$ and dose factors are from R. 6-3. (Koffman)

9. Verify that the output files written by the code write the data as is described in the files. (Koffman)

Review and Design Check of WSRC-TR-2005-00203

Larry D. Koffman

October 6, 2005

I have reviewed draft document WSRC-TR-2005-00203, Automated Groundwater

Screening, and I have performed the design check for items 6-9 in Appendix A, which gives the design check instructions. The version of the report that I reviewed is named "Intruder9+GW3 reporty.doc". Following are general review comments, the design check results, suggested changes, and a list of typos.

\section{$\underline{\text { General Review Comments }}$}

1. I understand the general thrust of the methodology discussion, but I had difficulty understanding the physical significance of the equations. It would be helpful if the equations could be explained in physical terms, e.g. why is SF proportional to leach rate, what is dilution volume, and what is the $\mathrm{X}$ term.

2. The terms in Eq 3 need to be defined with units. In particular, the $X_{0}$ term needs to be defined because in doing the design check I found that it differs from Eq 5 in that it includes leach rate. Why does $\mathrm{X}_{0}$ include leach rate when $\mathrm{SF}$ is already proportional to leach rate? Response: The leach rate used by the NCRP is that of the parent. $X_{0}$ is the parent fraction remaining as a source, hence, it is reduced by both leach and radioactive decay. Equation 5 is the fraction of progeny remaining and the methodology does not consider progeny transport.

3. Section 3.1.2.1 on trigger values leaves me baffled. I don't understand what trigger values are and as a result I can't appreciate why the current approach represents a benefit. Some insight about what trigger values are would be helpful. I think that it is related to the discussion about the impact of daughters with different leach rates and/or Kd, but I'm not sure. 
4. The document does make the point that the NCRP approach is not very clear and that the attempt is to implement the approach better that has been done in the past. I agree that the inclusion of full decay chains represents an improvement. Also, trying different options of following parents or daughters or a combination is a way to improve understanding toward better screening.

\section{$\underline{\text { Design Check }}$}

Item 6. Verify that the Automated Groundwater Screening coding has not adversely affected the Automated Intruder Analysis.

I used two approaches to verify that the changes in the Intruder coding did not cause any changes in the Intruder calculation and results. First, I examined the actual coding with the software Araxis Merge that is a very good file comparison program. I found that the only changes were in the form file Intruder9.frm and the module RadDecayCalcs9s.bas. In each of these there were some array dimension changes as explained in Section 3.2.3 and these changes would do no harm. Intruder9.frm had some coding in Form_Load that allowed the groundwater screening code to load decay input for decay chain calculations. This coding is only used if the Long option is chosen. This option should not be used for the Intruder calculation.

The second approach was to run an Intruder calculation of a slit trench using the post-drilling and resident scenarios. The same calculation run from the Groundwater Screening interface produced identical results.

I did find a problem in the IntruderInputLong.xls file relative to the intruder calculation. The Short inputs are used for the intruder calculation but these inputs are not the same as the approved inputs for the Intruder program. The current list in IntruderInputLong.xls has 103 nuclides and the approved list has only 78. In fact, the intruder program fails if the current list of 103 parents is used because there is an array dimension of 100 that is exceeded. I recommend that each of the Short worksheets be corrected to agree with the approved input. The bottom of page 13 has a reference as to why the Short worksheets are larger. This reference should be removed and a statement should be added somewhere that the Short worksheets agree with the approved inputs.

I found one other user interface problem on the first screen. The screen opens with the intruder analysis chosen and if run, runs correctly. If the user chooses the groundwater screening and then goes back to the intruder, the Long option is left chosen and if run, fails. I recommend adding coding to force the intruder analysis to use the Short option. The following coding is suggested.

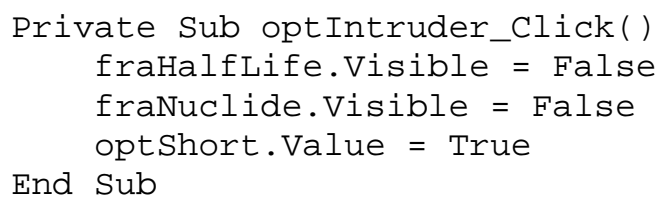


WSRC-TR-2005-00203, REVISION 0

Item 7. Verify that the equations of the report are correctly implemented in the coding.

I went through the coding and verified that the coding correctly implements the equations in the report. However, there is one caveat. The logic for indices into arrays is only correct if all parents are selected. That is, the calculations would not be correct for a subset (it turns out that choosing a subset fails because of an array dimension mismatch). I recommend removing the option to use a subset in the application and changing the text in the report accordingly (e.g. on p. 14). Response: Done.

There is an associated caution in setting up the input files GroundwaterInput.xls and IntruderInputLong.xls. The Kd worksheet in GroundwaterInput.xls and the Long worksheets in IntruderInputLong.xls must have the same number of nuclides listed in exactly the same order since the arrays are set up from these lists. I have confirmed that the lists are consistent for the current input files. However, if additions are made in the future to the Long inputs, this requirement must be met.

Item 8. Verify that the $k_{d} s$, half lives, and dose factors are input correctly. The $k_{d} s$ and dose factors are from R. 6-3.

I have gone through the coding in the Form_Load routine of frmGW.frm and have verified that the Excel file GroundwaterInput.xls is read correctly to populate the arrays NuclideGW, Kd, ParentDecayConst, DoseFactor, SigDaughters, and SigDaughtersSF. The parameter values are also read correctly to initialize the Groundwater Screening form. I also verified that the user inputs for parameters on the Groundwater Screening form are correctly read from the form into the program.

Item 9. Verify that the output files written by the code write the data as is described in the files.

I have gone through the coding in the subroutines described in Section 3.2.1.3 and have verified that the output is written as described and is done correctly with one small exception: in the Excel file the parameter value for water consumption is written in $\mathrm{m} 3$ but the unit is listed as liters. I believe that the intent was to write the value as liters and this correction should be make.

In the Word file, I noticed that the list of parameters is missing the travel time, which I think is an oversight that should be corrected.

In the Excel file, I suggest that the units for dose be included in the header since both mrem and $\mathrm{Sv}$ are referenced (I checked that the units are mrem).

The output in the Excel file with header "Sig Daughter List, not on parent list" is confusing. I suggest clarifying within the Excel file. The explanation in Section 3.3.3 is fairly clear. I suggest including a explanation of this output in Section 3.2.1.3 where output is discussed. 
I was unable to reproduce the tables in the report using the default parameter values. I looked back at some of your results and I was finally able to find that you had used a soil density of 1500, but the current code is picking up the intruder value of 1400 . There was a small difference in dilution volume with the default being 44 and your value 45 . When I put in the density of 1500 and dilution volume of 45 , I was able to recover the results in the tables in the report. Somewhere you need to state clearly the parameter values used to generate the tables.

\section{$\underline{\text { Suggested Changes or Additions }}$}

- An extraneous file, Debug.txt, is created in frmGW.frm in Sub RunScreening - remove this file creation

- If the Groundwater Screening form is closed with the upper right $X$, then the app is left hanging with EXCEL and WinWord running. If I kill the app, then WinWord is still hanging. I suggest adding Form_Unload to close the app gracefully if a user uses the X.

- When I open IntruderInputLong.xls it asks about macros and does not show a window. I suggest removing the macros and cleaning up the windows so that they open on lower screen resolutions. Likewise, remove the macros from GroundwaterInput.xls and resize the windows.

- On p. 4, "At high $\mathrm{k}_{\mathrm{d}} \mathrm{s}$ " - suggest "For high values of $\mathrm{k}_{\mathrm{d}}$ "

- On p. 4, "for the $\mathrm{k}_{\mathrm{d}} \mathrm{s}$ in" - suggest "for $\mathrm{k}_{\mathrm{d}}$ in"

- On p. 4, "The units are shown as $\mathrm{m}^{3} \mathrm{~kg}^{-1}$," - suggest adding after comma "which is the same as $1 \mathrm{~g}^{-1}$,

- At top of p. 5 the quote contains "for radionuclide" - looks funny, check quote.

- On p. 6, I couldn't reconcile the units for Eq 4. Give units for SF. I think $U_{D w}$ and V should have same units. Also define the summation limit n. I think the travel time should be for unretarded radionuclide. I suggest adding an $i$ index to the DF term as $\left(\mathrm{DF}_{\text {ing }}\right)_{i}$

- I believe that the indices in Eq 5 are really messed up including the summation and product limits. Check source and correct. Response: The indices are as shown the the source, R. 6-2. With the methodology adopted by this analysis, that equation is not used in the determination of the screeing factor. It is included for the exposition of the NCRP methodology. An equivalent method from R. 6-1 for computing the remaining fraction of a child is used.

- On p. 7, I believe that decay fraction is what we usually call branching fraction, so you might put "decay or branching fraction"

- On p. 7 in the paragraph above Eq 6, I think there are problems with the equation numbers. I think the first two "Equation 3" should be "Equation 4" and the "Equation 1" should be "Equation 4".

- In Eq 6, add an $i$ index to the DF term as $\left(\mathrm{DF}_{\text {ing }}\right)_{i}$

- In Section 3.1.3.1, for the sentence "Chains was also used to generate the decay chains for the intruder analysis" the word "generate" should be changed to "verify".

- On p. 21 in Table 3-5, I notice that the additional screened nuclide Ge-68 has a small dose by Eq 6. Maybe a comment is warranted in the discussion. 
- Introduction to Section 5 says there are two areas but more has been added - fix introductory statement.

Typos

- The long list of radionuclides has 825 , not 825 . Change all occurrences of 826 to 825 .

- On p. 20, "Table 3-5 is only 88 long" - the correct number is 86 .

- On p. 8, the second line from the bottom has "introduces" that should be "introduced"

- On p. 11, the text in the box by Equation 4 is hidden - increase the box size.

- On p. 13, second paragraph from bottom, option should be plural.

- On p. 19, fifth line, "rather versus" - delete rather

- On p. 19, line 8 - is word "vice" correct here?

- On p. 19, third line from bottom, radionuclide should be plural

- Page breaks are needed before tables 3-4 and 3-5

- In references, initials for R.6-1 should not be italicized and Oak Ridge should be two words in R.6-4. 


\section{Appendix B. Reviewer Comments}

The following Reviewer Comments were provided by Maurice Ades of Solid Waste. Author responses to the comments are in italics. Responses have been discussed with Mr. Ades.

\section{AUTOMATED GROUNDWATER SCREENING WSRC-TR-2005-00203, Rev. 0}

\section{Summary of Review Items}

\section{General Comments:}

1. Analyze the $\%$ differences shown in Table 3-3 and their physical significance.

2. Analyze the trends in doses and the benefits obtained by using daughters with their leach rates (Table 3-4) versus the automated groundwater results obtained (Table 3-3).

3. Outline the advantages and disadvantages of the method of analyzing daughters with their leach rates.

After discussion with Mr. Ades various sections of text were added to address these general comments. A table was added to enhance the added text. 


\section{Specific Comments:}

1. Page 2, Sec.2.0:

Provide a Reference for the calculational methods mentioned.

"Calculational methods" was a general comment and there is no specific reference.

2. Page 3:

The variables of equation 1 should be properly defined with their units. Similarly, provide the units of Phi.

Done.

3. Page 4, top:

Is there a physical meaning why the porosity in Eq. (2) should be multiplied by the saturation?

Text added.

4. Page 4, bottom:

State what is being reported by the NCRP for the time of the screening factor.

The NCRP does not give times, as was stated in the text.

5. Page 5, Sec.3.1.1.4:

What is the explanation for the U-234 screening factor? Can it be a printing error, 5.8E-12 instead of 5.0E-12 SvBq-1?

The authors of this report cannot explain the reasons for what is contained in the NCRP report.

6. Page 5:

Define the variables of Eq.(3) and their units.

Done.

7. Page 6:

Give Reference(with date) of the WITS inventory of $47 \mathrm{MCi}$.

Done.

8. Page 6, Eq.(4): 
- The expression given for $\mathrm{A} 0$ does not include a retardation coefficient (see WSRC-TR-2004-00294 for example). Do the authors assume that this coefficient is equal to 1? Justify.

Corrected typo in equation.

- Give the units for T travel.

Done

9. Page 7, Eq. (5):

Define $\mathrm{k}$

Define the subscript $\mathrm{h}$.

Done.

10. Page 7:

- Give the Reference for the Intruder Analysis mentioned.

Done.

- Where is the Pu-241 and Np-237 screening example shown.

Table 3-3 Comparison of Previous Analyses with Automated

Screening.

- What is the basis for using only the two greatest branching fractions in the decay chains.

As stated in the text there are few isotopes with more than 2

branching fraction and the third fraction is less than $10^{-5}$.

This is the path selected by the Intruder Analysis and since that engine is used for the decay chain calculations in the automated groundwater analysis, that is what is used.

11. Page 8:

The discrepancies between the half life data shown in Table 3-1 are significant.

I suggest using one set of approved data for all PA analyses. (Please check with Tom Butcher).

A section was added to Future Work to address this concern.

12. Page 11, Fig. 3-2:

Write the Equation numbers in the calculations shown on the flowchart.

Done.

13. Page 13, Sec.3.2.2, $2^{\text {nd }}$ paragraph:

Last sentence is unclear.

Rewritten.

14. Page 17, Table 3-3:

Ref. 1 is actually Ref. 2 (J. Cook's results).

Corrected.

The dose for Cf-249 may be in error (too low).

It s not too low. Resolved this through phone conversations. 
15. Page 19:

End of first paragraph is unclear.

Stet.

16. Page 19-20, Table 3-4:

- Units of the doses calculated are missing (mrem/ 1.E7 Ci). Added.

- It is not clear how the doses were calculated. Provide the calculational sequence using Eq. (6).

The doses were calculated as in R. 6-3.

- Provide a comparison between the doses in Table 3-4 and Table $3-3$. Is there any clear trend in the dose results by using Eq. (6)? See response to general comments.

- There is a huge discrepancy between the results of Table 3.3 and 3.4 for Cf-249. This may be an error. Please see Comment\# 14 above.

See response to general comments.

17. Page 20, Conclusions:

Indicate where Ge-68 failed the screening.

Done.

18. Section 5.1:

Indicate what the seven discrete times are.

Done

19. Note: Table 3-2 on page 18 should be Table 3-3.

Corrected. 
WSRC-TR-2005-00203, REVISION 0

\section{Appendix C. WITS email}

William Knopf/WSRC/Srs

05/11/2005 02:38 PM

To Glenn Taylor/SRNL/Srs@Srs

Cc Leonard Collard/SRNL/Srs@Srs, Don Sink/BSRI/Srs@Srs

bcc

Subject Re: WITS question

You are being misled by the side-effects of a work-around being used to track beryllium and elemental carbon. Because we are required to track these items but have no WITS capability to track them, we are forced to use the only mechanism that WITS currently has for checking limits:

radionuclides. They are being entered into WITS in quantities equal to the actual weights of these materials. That produces artificially high values for activity. To get the correct values, delete out any contributions from "BE1" and "C1". This should drop the EAV total from $4.6995 \mathrm{E}+7 \mathrm{ci}$ to $5.0379 \mathrm{E}+6 \mathrm{ci}$. Deleting contributions from packages not stored and those in "Empties" (which are packages whose contents were actually repackaged into others) reduces this further, but by an amount not visible at this level of precision. $5.0379 \mathrm{E}+6 \mathrm{ci}$ should be a good total activity for all locations defined in "EAV" (including temporary storage areas). This value is for all radionuclides tracked by WITS.

To ease the effort of deleting any radionuclides that you wish to exclude, run the same report you describe below, close the report, then click the Export button. This will create to Excel documents located in the folder c: \Program Files\WITS Reports. One file breaks the data down by unit/cell, while the other divides it only by location. With these spreadsheets its easy to sort then delete any items you wish to exclude.

Please let me know if you have any questions.

Glenn Taylor/SRNL/Srs

05/11/2005 01:33 PM

To William Knopf/WSRC/Srs@Srs

Cc Leonard Collard/SRNL/Srs@Srs

Subject WITS question

Bill,

Len Collard and I are trying to get a document out and Maurice asked about a number Len put in. The text in question is:

"The screening analysis introduces a 10 million $\mathrm{Ci}$ inventory for each radionuclide. However, no basis or reference is provided for this value. 
A recent check of WITS indicates that about 47 million $\mathrm{Ci}$ total are in the E-Area for those radionuclides that survived the screening. The results can be duplicated as follows:

Location

Isotope Inventory

EAV

All EAV Locations

Run Report

Examine last page."

Could you either confirm the 47 million $\mathrm{Ci}$ number or give us a better one? If there is a problem with determining "those radionuclides that survived the screening", see the attachment.

Maurice's comment is:

"Give Reference(with date) of the WITS inventory of $47 \mathrm{MCi} . "$

Thanks

Glenn Taylor

$773-41 \mathrm{~A}$

Savannah River National Laboratory

Aiken, SC 29808

$803-725-5823$

803-725-2978 (fax) 
Page Left Intentionally Blank 


\section{DISTRIBUTION:}

J. C. Griffin, 773-A

W. E. Stevens, 773-A

B. T. Butcher, 773-43A

E. L. Wilhite, 773-43A

J. R. Cook, 773-43A

L. B. Collard, 773-43A

L. D. Koffman, 773-42A

W. T. Goldston, 705-3C

D. F. Sink, 704-56E

M. J. Ades, 705-3C 